\title{
Vulnerability of Barley to African Pathotypes of Puccinia graminis f. sp. tritici and Sources of Resistance
}

\author{
B. J. Steffenson, A. J. Case, Z. A. Pretorius, V. Coetzee, F. J. Kloppers, H. Zhou, Y. Chai, R. Wanyera, \\ G. Macharia, S. Bhavani, and S. Grando
}

First, second, sixth, and seventh authors: Department of Plant Pathology, University of Minnesota, St. Paul 55108; third author: Department of Plant Sciences, University of The Free State, Bloemfontein, Republic of South Africa 9300; fourth and fifth authors: Pannar Seed (Pty) Ltd., P.O. Box 19, Greytown, Republic of South Africa 3250; eighth and ninth authors: Kenyan Agricultural and Livestock Research Organization, Njoro, Kenya; tenth author: International Maize and Wheat Improvement Center, Apdo. Postal, 6-641, 06600, Mexico, D.F.; and eleventh author: International Center for Agricultural Research in the Dry Areas, P.O. Box 114/5055, Beirut, Lebanon $1108-2010$.

Accepted for publication 26 March 2017.

\begin{abstract}
The emergence of widely virulent pathotypes (e.g., TTKSK in the Ug99 race group) of the stem rust pathogen (Puccinia graminis $\mathrm{f}$. sp. tritici) in Africa threatens wheat production on a global scale. Although intensive research efforts have been advanced to address this threat in wheat, few studies have been conducted on barley, even though pathotypes such as TTKSK are known to attack the crop. The main objectives of this study were to assess the vulnerability of barley to pathotype TTKSK and identify possible sources of resistance. From seedling evaluations of more than 1,924 diverse cultivated barley accessions to pathotype TTKSK, more than $95 \%(1,844)$ were found susceptible. A similar high frequency (910 of $934=97.4 \%$ ) of susceptibility was found for the wild progenitor (Hordeum vulgare subsp. spontaneum) of cultivated barley. Additionally, 55 barley lines with characterized or putative introgressions from various wild Hordeum spp. were also tested against pathotype TTKSK but none was found resistant. In total, more than $96 \%$ of the 2,913 Hordeum accessions

tested were susceptible as seedlings, indicating the extreme vulnerability of the crop to the African pathotypes of $P$. graminis f. sp. tritici. In total, 32 (1.7\% of accessions evaluated) and $13(1.4 \%)$ cultivated and wild barley accessions, respectively, exhibited consistently highly resistant to moderately resistant reactions across all experiments. Molecular assays were conducted on these resistant accessions to determine whether they carried rpg4/Rpg5, the only gene complex known to be highly effective against pathotype TTKSK in barley. Twelve of the $32(37.5 \%)$ resistant cultivated accessions and 11 of the $13(84.6 \%)$ resistant wild barley accessions tested positive for a functional Rpg5 gene, highlighting the narrow genetic base of resistance in Hordeum spp. Other resistant accessions lacking the rpg4/Rpg5 complex were discovered in the evaluated germplasm and may possess useful resistance genes. Combining rpg4/Rpg5 with resistance genes from these other sources should provide more durable resistance against the array of different virulence types in the $\mathrm{Ug} 99$ race group.
\end{abstract}

Stem rust is considered one of the most important plant diseases because it can cause complete destruction of one of mankind's most important food crops, wheat (Triticum aestivum L.), over a wide area and in a very short period of time. Due to its worldwide importance on a major world food crop, the wheat stem rust fungus (Puccinia graminis f. sp. tritici Erikss. \& Henning) is one of the most intensively studied plant pathogens, particularly with regard to its biology, physiology, genetics, epidemiology, and, more recently, genomics (Duplessis et al. 2011; Leonard and Szabo 2005). On the host side, the body of literature on the resistance of wheat to stem rust is voluminous and has contributed greatly to our evolving knowledge of breeding plants for disease resistance.

Barley (Hordeum vulgare L.) also can be attacked by stem rust and, in fact, is host to two such pathogens: the wheat stem rust fungus ( $P$. graminis f. sp. tritici) and the rye stem rust fungus (P. graminis f. sp. secalis Erikss. \& Henning). The former is the most important and widespread stem rust pathogen on barley (Steffenson 1992), except in some areas of northern and central Russia (Gorbunova 1979). Stem rust can be a serious problem of barley in the major production areas of the Upper Midwest (especially North Dakota and Minnesota) and Pacific Northwest (Washington) in the

Corresponding author: B. J. Steffenson; E-mail address: bsteffen@umn.edu

*The $\boldsymbol{e}$-Xtra logo stands for "electronic extra" and indicates that one supplementary figure and three supplementary tables are published online.

(c) 2017 The American Phytopathological Society
United States, the Prairie Provinces of Canada (Cereal Rust Bulletin 2012; Steffenson 1992), and also in northeastern Australia (DillMacky et al. 1991). It also was reported infecting barley crops in East Africa (Eritrea, Ethiopia, Kenya, and Uganda), the Middle East (Yemen, Iran, and Iraq), Central Asia (Kazakhstan and Tajikistan), South Asia (Bhutan, Nepal, and Pakistan), the Caucasus region (Georgia), and South America (Uruguay) (D. Hodson, K. Nazari, M. Rahmatov, and S. German, personal communication). In the early part of the 20th century, barley grown in the Upper Midwest region of the United States and adjacent provinces of Canada suffered several epidemics during the same years (especially 1935 and 1937) as wheat (Roelfs 1978; Steffenson 1992). Since the mid-1940s, stem rust of barley has been kept under control through the widespread use of cultivars carrying the resistance gene Rpgl (Steffenson 1992). Other factors, however, have contributed to this long-lasting disease control such as (i) a now largely resistant wheat crop that has kept the pathogen population small; (ii) barley's mostly northern cultivation area and shorter maturation period contributing, in most years, to a delayed onset of rust infection on an already ripening crop; (iii) a basal level of resistance underlying that conferred by Rpgl; and (iv) removal of the pathogen's alternate host (various barberry species in the genus Berberis) from production regions, thereby eliminating an early and local source of inoculum as well as new virulence types of the pathogen generated through sexual hybridization (Roelfs 1982; Steffenson 1992). The barley Rpg1 monoculture was established over several million hectares in North America and, therefore, was extremely vulnerable to epidemics should a virulent pathotype of P. graminis f. sp. tritici ever arise. Indeed, in 1988, a pathotype (QCC, now designated QCCJB) of $P$. graminis f. sp. tritici with virulence for 
Rpg1 was first discovered in the northwestern Great Plains (Martens et al. 1989) and, a few years later (1990 to 1991), caused scattered losses on barley in both the Upper Midwest region of United States and eastern Prairie Provinces of Canada (Harder and Dunsmore 1991; Roelfs et al. 1993a,b). During this time, the frequency of pathotype QCCJB increased rapidly (reaching $>90 \%$ of all races identified from commercial fields in the United States in 1990) due to its ability to attack not only barley cultivars with Rpgl but also a few wheat cultivars in the central Great Plains (Roelfs et al. 1993a). Removal of these stem-rust-susceptible wheat lines from cultivation led to a concomitant decrease in pathotype QCCJB so that, by 1997, it was not detected on the crop in the annual rust surveys (McVey et al. 2002). Since the early 1990s, no significant losses have been reported due to stem rust on barley in the Upper Midwest region (USDA-ARS 2016). This example highlights the importance of removing susceptible hosts, whatever they may be, from the Great Plains epidemiological region.

Success also has been attained in controlling stem rust of wheat in the northern Great Plains of North America. Through the deployment of cultivars with multiple resistance genes, losses to stem rust in wheat have been minimal since the mid-1950s (Leonard and Szabo 2005; USDA-ARS 2016). Similar successes have been reported in Australia and other major wheat production areas through this same gene-pyramiding scheme (Bariana et al. 2007; Park 2007; Singh et al. 2004). However, the world is now faced with one of the greatest biotic threats to stable wheat production in more than 50 years: widely virulent $P$. graminis f. sp. tritici pathotypes from Africa (Singh et al. $2008,2015)$. In 1998, heavy stem rust infections were observed on wheat lines carrying the widely deployed resistance gene $\mathrm{Sr} 31$ in a field nursery in southwest Uganda. The stem rust isolate collected from this nursery was designated "Ug99" (an abbreviation for the country of origin and year it was received and processed for virulence analysis) (Pretorius et al. 2000) and was subsequently assayed for its virulence phenotype on 16 differential lines of wheat (Jin et al. 2008; Roelfs and Martens 1988). Isolate Ug99 was initially keyed to pathotype TTKS (Wanyera et al. 2006). Subsequent virulence typing on an additional set of four wheat differential lines (with $\mathrm{Sr}$ genes Sr24, Sr31, Sr38, and $\operatorname{SrMcN}$ ) led to the expanded and current pathotype designation of TTKSK (Jin et al. 2008).

Since it was first discovered in Uganda in 1998 (Pretorius et al. 2000), pathotype TTKSK has been detected across many countries in Africa (Egypt, Eritrea, Ethiopia, Kenya, Rwanda, Sudan, and Tanzania) and also in the Middle East (Iran and Yemen) (Nazari et al. 2009; RustTracker.org 2016; Singh et al. 2008). It is certain to spread to other countries given the ease by which rust urediniospores can be disseminated over long distances by wind and also international travelers. In addition to pathotype TTKSK, a number of other variants (i.e., TTKST, TTTSK, TTKSP, PTKSK, PTKST, TTKSF, TTKSF+Sr9h, TTKTK, TTKTT, TTHST, TTHSK, and PTKTK) in the "Ug99 race group" have been described (Patpour et al. 2016; Pretorius et al. 2012; RustTracker.org 2016; Singh et al. 2015), thereby complicating the process of screening and breeding for disease resistance. These widely virulent pathotypes are a major threat to food security because 90 to $95 \%$ of the world wheat acreage and 85 to $95 \%$ of breeding materials for various countries are susceptible (Singh et al. 2006; 2011).

Although not a major world food crop, barley is nonetheless an important staple for some of the most impoverished people living in the highlands of Ethiopia, Eritrea, Yemen, Tibet, Nepal, Ecuador, and Peru (Grando and Gomez Macpherson 2005). It is also a major food staple in some countries of North Africa, Central Asia, and the Baltic region (Grando and Gomez Macpherson 2005). In many Western countries, barley is an important component of the agricultural economy for its use as malt in brewing, animal feed, and also specialty foods (Ullrich 2011). Because stem rust can markedly decrease both the yield and quality of barley (Dill-Macky et al. 1991; Harder and Dunsmore 1991; Mwando et al. 2012), it is important that an investigation be made to assess the potential vulnerability of the crop to $P$. graminis f. sp. tritici pathotypes such as TTKSK and also identify possible resistance sources. Thus, the main objective of this study was to evaluate the reaction of a large and diverse collection of Hordeum germplasm to pathotype TTKSK at the seedling stage and assess the vulnerability of the crop. During the course of these evaluations, sources of resistance were discovered. A preliminary report of this work was previously published (Steffenson et al. 2012).

\section{MATERIALS AND METHODS}

Plant materials. For the stem rust evaluations, a large collection of barley cultivars, breeding lines, and landraces were obtained from various gene banks, research institutions, universities, private companies, and individual collaborators around the world. This germplasm $(1,924$ accessions in total) represents a broad sampling of the genetic diversity in cultivated barley. Data on the type of germplasm, originating institution, region or country where developed or cultivated, seed supplier or organization, seedling infection types (ITs) to pathotype TTKSK, corresponding adult plant reactions of selected seedling resistant accessions in the field, and results of molecular assays for functional resistance genes are given in Supplementary Table S1. In addition to cultivated barley, accessions of wild barley (H. vulgare subsp. spontaneum C. Koch.) Thell. (Supplementary Table S2) and barley lines with confirmed or suspected chromosomal introgressions from wild Hordeum spp. (i.e., $H$. vulgare subsp. spontaneum, $H$. bulbosum L., H. depressum (Scribn. \& Sm.) Rydb., H. compressum Griseb., H. brachyantherum Nevski, and $H$. bogdanii Wil.) (Supplementary Table S3) also were evaluated for their stem rust phenotype. The $H$. vulgare subsp. spontaneum germplasm (934 accessions in total) included 300 accessions of the Wild Barley Diversity Collection (WBDC), previously used in other disease resistance studies (Ames et al. 2015; Roy et al. 2010; Steffenson et al. 2007), as well as many other accessions across the geographic range of the subspecies. The vast majority of wild barley accessions were from the Fertile Crescent but a broad representation also was obtained from Central Asia, North Africa, and the Caucasus region. Most of the introgression lines in cultivated barley were developed from crosses involving $H$. bulbosum and $H$. vulgare subsp. spontaneum (Wendler et al. 2015) but a few were made using other Hordeum spp. (Schooler 1974; Schooler and Franckowiak 1981). To assess whether previously identified resistance genes in barley are effective against pathotype TTKSK, we tested the Rpgl source 'Chevron' (CIho 1111) (Powers and Hines 1933; Shands 1939), the Rpg2 source 'Hietpas-5' (CIho 7124) (Patterson et al. 1957), the Rpg3 source 'GAW-79' (plant introduction [PI] 382313) (Jedel 1990; Jedel et al. 1989), the rpg4/ Rpg5 sources 'Q21861' (PI 584766) (carrying in addition Rpg1) and 'Q/SM20' (a Q21861/‘SM89010' doubled-haploid progeny carrying only rpg4/Rpg5) (Brueggeman et al. 2008; Jin et al. 1994; Sun et al. 1996; Sun and Steffenson 1997) (B. Steffenson, unpublished), the rpg6 source '212Y1' (Fetch et al. 2009), and the rpgBH (formerly designated $S$ gene) source 'Black Hulless' (PI 24849) (Steffenson et al. 1984; Sun and Steffenson 2005). Susceptible controls included 'Hiproly' barley (PI 60693) and the barley landrace PI 532013, which is extremely susceptible to stem rust at both the seedling and adult plant stages (B. Steffenson, unpublished). In addition, 'Line E' (PI 357308) and 'McNair 701' (CItr 15288) were included as susceptible wheat controls. Previous research revealed that accessions carrying genes at the complex rpg4/Rpg5 locus are resistant to pathotype TTKSK (Steffenson et al. 2009); thus, Q21861 and Q/SM20 also were considered to be resistant controls in the experiments.

Plant growth environment, inoculation protocol, and infection/incubation conditions for seedling evaluations. Seedling evaluations of all germplasm to stem rust pathotype TTKSK were done at the Minnesota Agricultural Experiment Station/Minnesota Department of Agriculture Plant Growth Biosafety Level-3 (BSL3) Containment Facility on the St. Paul campus of the University of 
Minnesota. Five seeds of each accession were planted into individual peat pots ( 7.0 in diameter by $9.0 \mathrm{~cm}$ in height) supported within plastic flats, each holding 16 pots. The growth media used was a 50:50 mixture of steam-sterilized native soil and Sunshine MVP mix (Sungro Horticulture Distributors, Quincy, MI), a growing medium containing vermiculite, Canadian sphagnum peat moss, coarse perlite, starter nutrient charge, gypsum, and dolomitic limestone. Plants were fertilized at planting with Osmocote 14-14-14 (0.3 g/ pot; Scott's Company, Marysville, $\mathrm{OH}$ ) and Peters Dark Weather 150-15 (40 g/liter at 1/16 dilution; Scott's Company) formulations. To break possible seed dormancy in the accessions and achieve more uniform plant growth for infection, the planted seed were initially incubated at $4^{\circ} \mathrm{C}$ for 2 to 5 days. Then, they were brought into the BSL-3 greenhouse and grown at 19 to $22^{\circ} \mathrm{C}$ with supplemental lighting provided by $400-\mathrm{W}$ high-pressure sodium lamps emitting photons at a minimum of $300 \mu \mathrm{mol} \mathrm{s}-1 \mathrm{~m}^{-2}$ for $14 \mathrm{~h} /$ day.

A single pustule isolate (04KEN156/04) of pathotype TTKSK (Jin and Singh 2006; Steffenson et al. 2009) was used in all experiments and increased on susceptible McNair 701 wheat. Urediniospores were collected with a cyclone spore collector (G-R Manufacturing Co., Manhattan, KS) (Browder 1971), desiccated over a saturated salt solution at approximately $20 \%$ relative humidity $(\mathrm{RH})$, and stored in size 00 gelatin capsules (Gallipot Inc., St. Paul, MN) enclosed within cryovials (Corning Life Sciences, Tewksbury, MA) in an ultralowtemperature freezer $\left(-80^{\circ} \mathrm{C}\right)$ until needed. In the morning before inoculation, the rust was removed from the freezer and immediately heat shocked in a water bath at $45^{\circ} \mathrm{C}$ for $15 \mathrm{~min}$ (Rowell 1985). Then, the rust was rehumidified for at least $3 \mathrm{~h}$ by incubating the opened gelatin capsules over a saturated salt solution at approximately $80 \%$ $\mathrm{RH}$. Germination tests for the rust were performed by spraying a suspension of urediniospores dispersed in a lightweight mineral oil (Soltrol 170; Phillips Petroleum, Bartlesville, OK) onto Petri plates containing $2 \%$ water agar, incubating the plates at $22^{\circ} \mathrm{C}$ for at least $3 \mathrm{~h}$ in the dark, and then examining 100 to 200 arbitrarily selected urediniospores for extended germtubes with a compound microscope at $\times 40$. Occasionally, fresh rust, newly collected from infected plants, was used for inoculation. In either case, the germination rate of urediniospores was $90 \%$ or higher.

For inoculation, urediniospores were placed into new gelatin capsules containing the oil carrier (concentration of $15 \mathrm{mg}$ of urediniospores per $0.7 \mathrm{ml}$ of oil) and then applied to 9-day-old plants (fully expanded primary leaves) in each flat using special atomizers (G-R Manufacturing Co.) (Browder 1971) pressured by a pump set at 25 to $30 \mathrm{kPa}$. Urediniospores were applied at approximately $0.175 \mathrm{mg} / \mathrm{plant}$. The concentration of inoculum was approximately four times higher than that used in previous studies (Steffenson et al. 2009; Sun and Steffenson 2005) but was necessary to ensure good infection on barley within the drier, high-air-flow environment of the BSL-3. Immediately after inoculation, the plants were placed in front of a small electric fan for 3 to $5 \mathrm{~min}$ to hasten the evaporation of the oil carrier from leaf surfaces. Thereafter, an additional $90 \mathrm{~min}$ of evaporation time was provided to reduce the phytotoxicity of the oil carrier. Then, plants were placed in mist chambers and exposed to approximately $30 \mathrm{~min}$ of continuous misting from ultrasonic humidifiers, followed by $16 \mathrm{~h}$ of periodic misting ( $2 \mathrm{~min}$ of misting every $15 \mathrm{~min}$ ) in the dark. After the dark period, lights (400-W highpressure sodium vapor lamps emitting photons at $300 \mu \mathrm{mol} \mathrm{s}^{-1} \mathrm{~m}^{-2}$ ) were turned on to complete the final stages of the infection process while the misters continued to run under the same regime. After a minimum of $5 \mathrm{~h}$ of light exposure, the misters were turned off and chamber doors were opened, facilitating the slow drying of plant surfaces over the next several hours. When the plants were completely dry, they were moved back to the greenhouse under the conditions previously described. The general conditions used for the stem rust infection period were based on the methods of Rowell (1985).

Disease assessment. At 12 to 14 days after inoculation, the ITs on each accession were scored using a 0-to-4 scale. The IT scale used for barley is a modification of the one developed for wheat by Stakman et al. (1962) and is based primarily on uredinial size, as described by Miller and Lambert (1955). Plus (+) and minus (-) symbols were used denote more or less sporulation of classically described uredinia, respectively. Barley frequently exhibits two or more ITs on a single leaf (i.e., a mesothetic reaction) when infected with $P$. graminis (Sun and Steffenson 2005). All of the observed ITs were recorded in order of their frequency on the leaves; however, only the two most common ones (i.e., the IT mode) are presented in the data tables because they usually comprise more than $85 \%$ of all those observed on individual accessions (Zhou et al. 2014). ITs were classified into five general categories as follows: 0 or 0; ("zerofleck", a hypersensitive reaction) as highly resistant (HR), 1 as resistant (R), 2 as moderately resistant (MR), 3- as moderately susceptible (MS), and 3, 3+, or 4 as susceptible (S).

The experiment was conducted in a completely randomized design with one replicate and was repeated once. To obtain more robust data on germplasm likely to be used in breeding, accessions exhibiting consistently HR to MR reactions were repeated at least two additional times to confirm the phenotype. The same was done for accessions exhibiting variable reactions (i.e., reaction classes of $\mathrm{HR}, \mathrm{R}$, or MR versus MS or S) between experiments or those that showed clear segregation among individual plants. Some cultivated and wild barley accessions were only tested once due to seed quantity limitations but, in all of these cases, the plants exhibited only or predominantly $\mathrm{S}$ reactions to pathotype TTKSK. The resistant (Q21861 and Q/SM20) and susceptible (Hiproly, Line E, and McNair 701) controls were included approximately every 50 accessions to monitor both the infection levels and expected ITs in each experiment.

To provide a succinct summary of results from this large dataset, accessions were categorized into three groups: those exhibiting only $\mathrm{HR}$, R, or MR reactions across all experiments (accessions highlighted in green in Supplementary Tables S1 and S2); those exhibiting predominantly $\mathrm{HR}, \mathrm{R}$, or $\mathrm{MR}$ reactions within the IT mode across experiments (accessions highlighted in light green) or in individual plants of accessions that were phenotypically mixed due to possible segregation or seed admixtures (accessions highlighted in blue); and those exhibiting only or predominantly MS to $\mathrm{S}$ reactions within the IT mode across experiments (accessions not highlighted). The number and percentage of accessions in each of these three groups were summarized across continents/regions and countries for cultivated barley and across countries for wild barley.

Assessment of adult plant resistance in the field. Repeated attempts were made to obtain adult plant resistance data on the entire germplasm panels at the Kenyan Agricultural and Livestock Research Organization in Njoro, Kenya and in Greytown, South Africa; however, these efforts failed due to low rust infection. From 2009 to 2015, we focused our efforts on obtaining adult plant resistance data on a subset of Hordeum accessions exhibiting consistently low seedling ITs because previous studies revealed that such reactions were usually indicative of all-stage resistance. Still, in a number of these stem rust nurseries, the level of infection obtained was insufficient to reliably separate known S from R accessions. Thus, only data from the 2014 Kenya and 2012 and 2015 South Africa nurseries are presented. Methodology for initiating stem rust epidemics at the different locations was similar, and a completely randomized plot design with one replicate was used.

For the 2014 off-season Kenya nursery (planting in December with scoring in April), the protocols of Njau et al. (2013) were followed, except that needle inoculations of spreader plants (i.e., injecting a urediniospore-water suspension into stems) were made in addition to the direct foliar spray inoculations. The pathotypes used in Kenya consisted of a mixture of TTKSK (avirulence/virulence formula of Sr36, Tmp, 24/Sr5, 21, 9e, 7b, 11, 6, 8a, 9g, 9b, 30, 17, 9a, 9d, 10, 31, $38, M c N)$ and TTKST $(S r 36, T m p / S r 5,21,9 e, 7 b, 11,6,8 a, 9 g, 9 b, 30$, 
$17,9 a, 9 d, 10,24,31,38, M c N)$. The local susceptible wheat control 'Red Bobs' was included every 100 rows in the nursery to monitor the level of infection in the nursery.

In the South Africa rust nurseries, barley accessions were sown in 0.5 -m rows spaced $75 \mathrm{~cm}$ apart. Each barley row was flanked on one end by the stem-rust-susceptible bread wheat line L37-07. The barley screening trial formed part of a larger wheat stem rust screening nursery of approximately 10,000 lines, specifically designed to provide abundant $P$. graminis f. sp. tritici inoculum from numerous spreader rows and blocks. Beginning in early August of each year, stem rust epidemics were created by repeatedly spray inoculating susceptible spreader plants in the surrounding wheat nursery. For the inoculations, urediniospores suspended in Soltrol oil were applied onto plants with an ultra-low-volume sprayer (Micron Group, Bromyard, England) in the late afternoon. Then, strategically positioned spreader rows were covered with plastic sheeting to facilitate dew formation and, hence, infection by the pathogen. Pathotype PTKST $(S r 9 h, 21,27$, and $36 ; T m p / 5,6,7 b$, $8 a, 8 b, 9 a, 9 b, 9 d, 9 e, 9 g, 10,11,17,24,30,31,38$; and $M c N)$ was used in all experiments and bulk harvested on the day of inoculation from infected wheat seedlings (carrying Sr31) grown in a greenhouse. The local susceptible wheat control L37-07 was included every 100 rows in the nursery to monitor the level of infection in the nursery.

Adult plant resistance was assessed based on the severity of rust occurring on the stems and leaf sheaths of plants. Rust severity was visually estimated using the modified Cobb Scale (0 to 100\%) (Peterson et al. 1948) when plants were at the mid- to hard-dough stage of development (Zadoks et al. 1974). In addition to severity, accessions also were assessed for their adult plant infection response (IR) according to the scale of $\mathrm{R}=$ minute to small uredinia surrounded by chlorosis or necrosis, $\mathrm{MR}=$ medium-sized uredinia often surrounded by chlorosis, MS = medium to large erumpent uredinia with little or no chlorosis, and $\mathrm{S}=$ very large erumpent uredinia with little or no chlorosis (Roelfs et al. 1992). IRs were recorded in order of their relative frequency (e.g., MR-MS) when more than one was observed on an accession.

Molecular assays for the $R p g 5$ and $R p g 1$ stem rust resistance genes. The rpg4/Rpg5 gene complex (Brueggeman et al. 2008) is the only one known to confer a high level of all-stage resistance to pathotype TTKSK in barley (Steffenson et al. 2009). To determine whether the Hordeum accessions found to be resistant carried this gene complex, molecular assays were conducted for the functional Rpg5 resistance allele and its described susceptibility alleles. Genomic DNA from select resistant Hordeum accessions was extracted by the cetyltrimethylammonium bromide method and used for polymerase chain reaction (PCR) and sequencing applications (Murray and Thompson 1980). The primer pairs LRK-F1 (CTGCTGGCACAGAGTCTGCCTTGAG) versus LRK-R1 (ACT

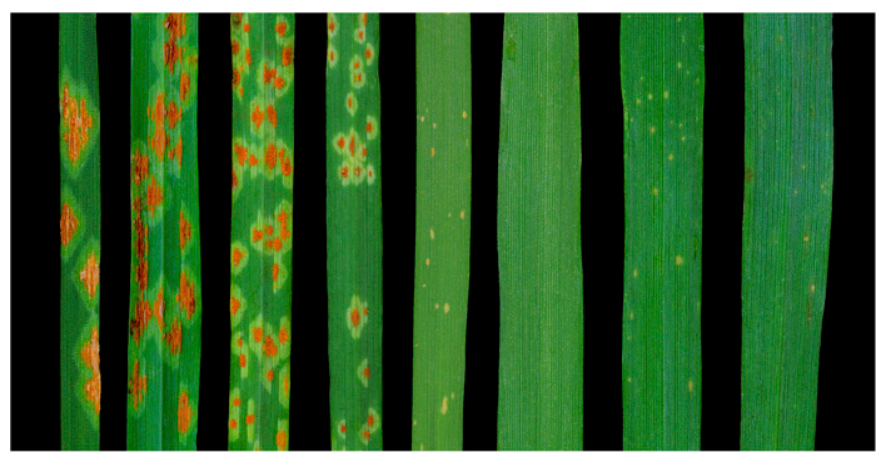

Fig. 1. Seedling infection types of wheat control McNair 701 and select cultivated and wild barley accessions to Puccinia graminis f. sp. tritici pathotype TTKSK in the greenhouse. Left to right: McNair 701 wheat and barley accessions PI 532013, Hiproly, WBDC123, WBDC119, Q21861, Brandham II, and SH98073.

TABLE 1. Summary of the infection type (IT) mode, range, and general reaction (GR) of controls and accessions with recognized stem rust resistance genes to Puccinia graminis f. sp. tritici pathotype TTKSK at the seedling stage, their corresponding adult plant reactions in the field, and results of molecular assays for functional resistance genes

\begin{tabular}{|c|c|c|c|c|c|c|c|c|c|c|c|}
\hline \multirow[b]{3}{*}{ Accession } & \multirow[b]{3}{*}{ Other ${ }^{d}$} & \multirow[b]{3}{*}{ Description } & \multirow{2}{*}{\multicolumn{3}{|c|}{$\begin{array}{c}\text { Seedling reaction } \\
\text { TTKSK }\end{array}$}} & \multicolumn{4}{|c|}{ Adult plant reaction ${ }^{\mathrm{a}}$} & \multirow{2}{*}{\multicolumn{2}{|c|}{ Assays $^{\mathrm{c}}$}} \\
\hline & & & & & & \multicolumn{2}{|c|}{ TTKSK/TTKST Kenya $^{\mathrm{b}}$} & \multicolumn{2}{|c|}{ PTKST South Africa } & & \\
\hline & & & $\mathrm{IT}^{\mathrm{e}}$ & Range $^{f}$ & $\mathrm{GR}^{\mathrm{g}}$ & Sev $(\%)$ & IR & Sev $(\%)$ & IR & $\overline{R p g 5}$ & RpgI \\
\hline Hietpas 5 & CIho 7124 & Source of Rpg2 & 3 & 3 & $\mathrm{~S}$ & $16(1-30)$ & MS-S & $10(0-15)$ & MR-MS & - & - \\
\hline GAW 79-3 & PI 382313 & Source of Rpg3 & $3-, 2$ & 2,1 to $3-, 2$ & MS-MR & $22(10-40)$ & MS-S & $31(5-50)$ & $\mathrm{S}$ & - & - \\
\hline Q21861 & PI 584766 & $\begin{array}{l}\text { Source of rpg4/Rpg } 5 \\
\text { plus Rpg1 }\end{array}$ & $0 ;, 1$ & $0 ;$ to 2,1 & HR-R & $2(0-5)$ & $\mathrm{R}-\mathrm{MR}$ & $4(0-30)$ & MR-R & + & + \\
\hline Black Hulless & PI 24849 & Source of $r p g B H$ & 3 & $3-$ to 3 & $\mathrm{~S}$ & $15(-)$ & S-MS & $66(5-95)$ & $\mathrm{S}$ & - & - \\
\hline Hiproly & PI 60693 & Susceptible barley control & 3 & $3-$ to 3 & $\mathrm{~s}$ & $23(5-70)$ & S-MS & $36(3-90)$ & S-MS & - & - \\
\hline PI 532013 & 2794 & Susceptible barley control & 3 & 3 to $3+$ & $\mathrm{S}$ & $53(25-80)$ & $\mathrm{S}$ & $71(12-100)$ & $\mathrm{S}$ & - & - \\
\hline McNair 701 & CItr 15288 & Susceptible wheat control & 4 & $3+$ to 4 & $\mathrm{~S}$ & $\ldots$ & ... & $\ldots$ & $\ldots$ & - & - \\
\hline Line $\mathrm{E}$ & CItr 357308 & Susceptible wheat control & 4 & 3 to 4 & $\mathrm{~S}$ & $\ldots$ & $\ldots$ & $\ldots$ & $\ldots$ & - & - \\
\hline
\end{tabular}

a Adult plant reaction was assessed at the mid- to hard-dough stage of development as the percentage of stem and leaf sheath tissue infected by stem rust, estimated using the modified Cobb scale (0 to 100\%) (Peterson et al. 1948), and also as the type of uredinia (i.e., infection response [IR]) observed, where $\mathrm{R}=$ resistant, MR = moderately resistant, $\mathrm{MS}=$ moderately susceptible, and $\mathrm{S}=$ susceptible (Roelfs et al. 1992). Adult plant severity and IR data are based on experiments conducted in Kenya from 2012 to 2015 and in South Africa from 2013 to 2015. Sev = average severity, with range in parentheses, and ... indicates data missing or not applicable.

b The 2014 Kenya nursery had a mixture of pathotypes TTKSK and TTKST.

c Molecular assays to determine a functional or nonfunctional Rpg5 gene were conducted according to the methods of Arora et al. (2013) and Mamo et al. (2015), and those for Rpgl were done according to Eckstein et al. (2003), as modified by Derevnina et al. (2014). Detailed descriptions of the assays are given in the Materials and Methods section. Symbols: + indicates the presence of the functional gene and a - indicates the lack of the functional gene.

d Other designator.

e ITs for wheat were scored based on the 0-to-4 scale of Stakman et al. (1962) and those for barley were scored based on the system of Stakman et al. (1962), as modified by Miller and Lambert (1955). The IT mode represents the one or two most common ITs observed in order of frequency on accessions over all experiments. Symbols + and - denote more or less sporulation of classically described uredinia, respectively. Seedling IT data are based on experiments conducted in 2014 and 2015.

${ }^{f}$ IT range is the lowest and highest types observed on accessions over all experiments.

${ }^{g}$ GR was assigned for the IT mode where 0 or 0 ; is highly resistant (HR); 1 is R; 2 is MR; $3-$ is MS; and 3, 3+, or 4 is $\mathrm{S}$. 
CTCGGGTCTGAAGTTCCGTGTG) or PP2C-R2 (CCCGAGG TTTGCGATGAAGAGAGTC) were used to distinguish functional Rpg5 alleles from the most common nonfunctional Rpg5 allele, which contains an insertion that replaces the protein kinase domain with a protein phosphatase domain (Brueggeman et al. 2008). The diagnostic primer combinations produce dominant markers consisting of amplicons across the LRR to STPK or LRR to PP2C junction and were previously described (Mamo et al. 2015). Accessions showing a predicted functional STPK domain were sequenced across the Rpg5 5' region that contains a single cytosine insertion, resulting in a rare nonfunctional rpg 5 allele as the result of a frame shift and nonfunctional truncated RPG5 protein (Arora et al. 2013; Brueggeman et al. 2008). To accomplish this, an amplicon was generated from the primer pair R5-F1 (CCGCCTACCACACCTCCGATTCCAC) versus R5-R1 (TCAGGTTTGATGGCTGTCTCTGGAG) and then directly sequenced with the R5-F1 primer. Functional Rpg 5 alleles contain the sequence GCAGGATCCCCCCATCACGG, whereas nonfunctional rpg5 alleles, such as 'Golden Promise', contain the sequence GCAGGATCCCCCCCATCACGG. Accessions were also sequenced across the 3' STPK domain region that contains a second rare susceptible rpg 5 allele, predicted to encode full-length proteins with a nonsynonymous nucleotide substitution that results in the amino acid substitution E1287A, as reported by Arora et al. (2013). For this protocol, an amplicon was generated using the primers RPG5F10 (TGCATCTATCTGCTCATGCAAGGAG) versus RPG5-R10 (AACAATATTCACCTGCGGCACCAAC). This product was then directly sequenced using the RPG5-SEQ-R1 (AGTGGCTTGA GAGCTTCAAC) primer (suggested by R. Brueggeman, personal communication). The sequencing results were translated and aligned using Vector-NTI software to determine whether the accessions contained predicted functional or nonfunctional RPG5 proteins. Accessions with functional Rpg5 alleles have the sequence TCCTTCCCCGCGAGGG or TCCTTCCCCACGAGGG, corresponding to groups $3 \mathrm{R}$ and $1 \mathrm{R}$, respectively, whereas accessions with nonfunctional rpg 5 alleles have the sequence TCCTTCCCCGCG CGGG, corresponding to group $4 \mathrm{~S}$, as described by Arora et al. (2013). Because genes at the rpg4/Rpg5 locus are tightly linked with each other, a positive assay for a functional Rpg 5 gene was presumed to be indicative for the presence of a functional rpg4/Rpg5 gene complex (Arora et al. 2013). In summary, genotypes with a functional Rpg5 gene (i) amplify a product from the LRK-F1 versus LRK-R1 PCR, (ii) do not amplify a product from the LRK-F1 versus PP2C reaction, (iii) do not contain the Golden Promise-like sequence within the amplicon generated by R5-F1 versus R5-R1, and (iv) possess either the group 3R- or 1R-like sequence within the amplicon of RPG5-F10 versus RPG5-R10.

Accessions resistant to pathotype TTKSK at the seedling stage were also assayed for the presence of Rpgl because it may confer a low level of residual resistance against virulent pathotypes as compared with accessions lacking any major resistance genes. Assays for a functional or nonfunctional Rpg1 gene were performed as described by Eckstein et al. (2003) using the revised primer sequence for the

TABLE 2. Summary of general reactions of cultivated barley accessions from different countries to Puccinia graminis f. sp. tritici pathotype TTKSK at the seedling stage

\begin{tabular}{|c|c|c|c|c|}
\hline \multirow[b]{2}{*}{ Continent, region, country } & \multicolumn{3}{|c|}{ Number $(\%)$ exhibiting reactions ${ }^{\mathrm{a}}$} & \multirow[b]{2}{*}{ Total $^{\mathrm{b}}$} \\
\hline & Only HR to MR & PD R to MR or Seg & Only or PD MS to S & \\
\hline \multicolumn{5}{|l|}{ North America } \\
\hline Canada & $9(6.0)$ & $2(1.4)$ & $138(92.6)$ & 149 \\
\hline United States & $2(0.4)$ & $19(3.6)$ & $502(96.0)$ & 523 \\
\hline Continent total & $11(1.6)$ & $23(3.4)$ & 647 (95.0) & 681 \\
\hline \multicolumn{5}{|l|}{ South America } \\
\hline Brazil & $0(0.0)$ & $1(3.2)$ & $30(96.8)$ & 31 \\
\hline Chile & $0(0.0)$ & $0(0.0)$ & $12(100.0)$ & 12 \\
\hline Ecuador & $0(0.0)$ & $0(0.0)$ & $10(100.0)$ & 10 \\
\hline Peru & $0(0.0)$ & $0(0.0)$ & $17(100.0)$ & 17 \\
\hline Uruguay & $2(14.3)$ & $0(0.0)$ & $12(85.7)$ & 14 \\
\hline Continent total & $2(1.9)$ & $1(1.0)$ & $101(97.1)$ & 104 \\
\hline \multicolumn{5}{|l|}{ Africa } \\
\hline Libya & $0(0.0)$ & $0(0.0)$ & $10(100.0)$ & 10 \\
\hline Morocco & $0(0.0)$ & $0(0.0)$ & $25(100.0)$ & 25 \\
\hline South Africa & $0(0.0)$ & $0(0.0)$ & $7(100.0)$ & 7 \\
\hline Tunisia & $0(0.0)$ & $0(0.0)$ & $9(100.0)$ & 9 \\
\hline Continent total & $0(0.0)$ & $0(0.0)$ & 104 (100.0) & 104 \\
\hline \multicolumn{5}{|l|}{ Asia } \\
\hline Afghanistan & $0(0.0)$ & $0(0.0)$ & $10(100.0)$ & 10 \\
\hline Armenia & $0(0.0)$ & $0(0.0)$ & $7(100.0)$ & 7 \\
\hline Azerbaijan & $0(0.0)$ & $0(0.0)$ & $2(100.0)$ & 2 \\
\hline Bangladesh & $0(0.0)$ & $0(0.0)$ & $2(100.0)$ & 2 \\
\hline China & $3(8.1)$ & $0(0.0)$ & $34(91.9)$ & 37 \\
\hline Cyprus & $0(0.0)$ & $0(0.0)$ & $1(100.0)$ & 1 \\
\hline Georgia & $0(0.0)$ & $0(0.0)$ & $10(100.0)$ & 10 \\
\hline
\end{tabular}

${ }^{a} \mathrm{PD}=$ predominantly and $\mathrm{Seg}=$ segregating. A general reaction was assigned to the infection type (IT) mode where 0 or 0 ; is highly resistant (HR); 1 is resistant (R); 2 is moderately resistant (MR); 3- is moderately susceptible (MS); and 3,3+, or 4 is susceptible (S). Then, accessions were categorized into three groups: those exhibiting only HR, R, or MR reactions across all experiments; those exhibiting predominantly HR, R, or MR reactions within the IT mode across experiments or in individual plants of accessions that were phenotypically mixed due to possible segregation or seed admixtures; and those exhibiting only or predominantly MS to $\mathrm{S}$ reactions within the IT mode across experiments.

b Total number evaluated. 
functional Rpgl allele of RPG1-N-F (CGGCTAATCACATCAAG TAA) versus RPG1-N-R (AGCCCATCATCAATAGACAA) and the primer pair for the nonfunctional rpgl allele of RPG1-S-F (GGCTAATCACATCAAGGTT) and RPG1-S-R (CCACGACCA ATTATGTTCTG), as described by Derevnina et al. (2014). The primer combinations produce dominant markers consisting of amplicons in either the functional or nonfunctional PCR assay.

Molecular assays and sequencing for Rpg5 and Rpg1 were done by Functional Biosciences, Madison, WI.

\section{RESULTS}

Seedling evaluations in the greenhouse. Reaction of susceptible controls and accessions with recognized stem rust resistance genes. The data presented in Table 1 provide an overall summary of the degree of central tendency and range observed for ITs of the controls and carriers of known resistance genes across experiments. Susceptible controls were included in multiple replicates in all experiments to monitor the infection level and virulence phenotype of pathotype TTKSK. Moderate to high infection levels were observed in all experiments, allowing for reliable scoring of ITs on the Hordeum accessions. Barley (Hiproly and PI 532013) and wheat (McNair 701 and Line E) controls all exhibited the expected compatible IT modes of 3 and 4, respectively (Table 1; Fig. 1).

Hietpas-5 (Rpg2) and Black Hulless ( $r p g B H$ ) exhibited S ITs (IT mode 3), similar to the susceptible controls Hiproly and PI 532013
(Table 1). Chevron (Rpg1), GAW-79 (Rpg3), and 212Y1 (rpg6) all exhibited predominantly MS ITs but with some MR types at lower frequency (IT mode 3-, 2). Accessions carrying the gene complex of rpg4/Rpg5 (Q21861 and Q/SM20) were HR to R, exhibiting IT modes of 0;, 1, and 1, 0;, respectively. Q21861, carrying Rpg1 in addition to rpg4/Rpg5, exhibited a higher proportion of $\mathrm{HR}$ (i.e., hypersensitive IT 0; ) reactions (Fig. 1) than Q/SM20, carrying only the rpg4/Rpg5 complex (Table 1 ).

Reaction of cultivated barley accessions. Of the 1,924 cultivated barley accessions evaluated to pathotype TTKSK, only $32(1.7 \%)$ exhibited consistently HR to MR reactions (IT modes 0 ; to 2) across all experiments (Table 2). Many of these accessions exhibited the full range of resistant class ITs from 0 ; to 2 across the three experiments (Table 3). However, some exhibited predominantly IT 0; (e.g., 'Anakin'), whereas others exhibited predominantly IT 2 (e.g., ND23821, CLE 202, BHS 248, Cantala, and Tallon). Resistance was identified from 13 of the $59(22.0 \%)$ countries from which germplasm was tested, located on the continents of North America, South America, Asia, Europe, and Australia (Table 2). Nine countries had more than one resistant accession: Canada with nine, United States with two, Uruguay with two, China with three, Denmark with four, France with two, Russian Federation with two, United Kingdom with two, and Australia with two. Nearly all of the resistant accessions identified were cultivars or breeding lines from different barley improvement programs around the world, the exception being Brandham II (Fig. 1), a landrace from Austria (Table 3; Supplementary Table S1).

TABLE 2. (continued from preceding page)

\begin{tabular}{|c|c|c|c|c|}
\hline \multirow[b]{2}{*}{ Continent, region, country } & \multicolumn{3}{|c|}{ Number $(\%)$ exhibiting reactions $\mathrm{s}^{\mathrm{a}}$} & \multirow[b]{2}{*}{ Total $^{\mathrm{b}}$} \\
\hline & Only HR to MR & PD $\mathrm{R}$ to $\mathrm{MR}$ or $\mathrm{Seg}$ & Only or PD MS to $S$ & \\
\hline India & $1(5.6)$ & $1(5.6)$ & $16(88.8)$ & 18 \\
\hline Iran & $0(0.0)$ & $0(0.0)$ & $9(100.0)$ & 9 \\
\hline Iraq & $0(0.0)$ & $1(10.0)$ & $9(90.0)$ & 10 \\
\hline Israel and adjacent territories & $0(0.0)$ & $1(8.3)$ & $11(91.7)$ & 12 \\
\hline Japan & $0(0.0)$ & $0(0.0)$ & $19(100.0)$ & 19 \\
\hline Jordan & $0(0.0)$ & $0(0.0)$ & $10(100.0)$ & 10 \\
\hline Kazakhstan & $0(0.0)$ & $0(0.0)$ & $9(100.0)$ & 9 \\
\hline Kyrgyzstan & $0(0.0)$ & $0(0.0)$ & $10(100.0)$ & 10 \\
\hline Nepal & $0(0.0)$ & $0(0.0)$ & $2(100.0)$ & 2 \\
\hline Pakistan & $0(0.0)$ & $0(0.0)$ & $10(100.0)$ & 10 \\
\hline South Korea & $0(0.0)$ & $1(5.0)$ & $19(95.0)$ & 20 \\
\hline Syria & $0(0.0)$ & $0(0.0)$ & $21(100.0)$ & 21 \\
\hline Tajikistan & $0(0.0)$ & $0(0.0)$ & $10(100.0)$ & 10 \\
\hline Turkey & $0(0.0)$ & $0(0.0)$ & $16(100.0)$ & 16 \\
\hline Turkmenistan & $0(0.0)$ & $0(0.0)$ & $9(100.0)$ & 9 \\
\hline Uzbekistan & $0(0.0)$ & $0(0.0)$ & $7(100.0)$ & 7 \\
\hline Yemen & $0(0.0)$ & $1(10.0)$ & $9(90.0)$ & 10 \\
\hline Continent total & $4(1.5)$ & $5(1.8)$ & $262(96.7)$ & 271 \\
\hline \multicolumn{5}{|l|}{ Europe } \\
\hline Austria & $1(11.1)$ & $0(0.0)$ & $8(88.9)$ & 9 \\
\hline Czech Republic & $0(0.0)$ & $0(0.0)$ & $1(100.0)$ & 1 \\
\hline Denmark & $4(19.1)$ & $2(9.5)$ & $15(71.4)$ & 21 \\
\hline Finland & $0(0.0)$ & $0(0.0)$ & $1(100.0)$ & 1 \\
\hline France & $2(3.1)$ & $1(1.6)$ & $61(95.3)$ & 64 \\
\hline Germany & $1(1.9)$ & $0(0.0)$ & $52(98.1)$ & 53 \\
\hline Italy & $0(0.0)$ & $0(0.0)$ & $47(100.0)$ & 47 \\
\hline Netherlands & $0(0.0)$ & $0(0.0)$ & $16(100.0)$ & 16 \\
\hline Norway & $0(0.0)$ & $0(0.0)$ & $8(100.0)$ & 8 \\
\hline Russian Federation & $2(1.7)$ & $6(5.3)$ & $107(93.0)$ & 115 \\
\hline Spain & $1(2.4)$ & $0(0.0)$ & $41(97.6)$ & 42 \\
\hline Sweden & $0(0.0)$ & $0(0.0)$ & $27(100.0)$ & 27 \\
\hline Switzerland & $0(0.0)$ & $0(0.0)$ & $7(100.0)$ & 7 \\
\hline United Kingdom & $2(0.8)$ & $10(4.1)$ & $231(95.1)$ & 243 \\
\hline Continent total & $13(2.0)$ & $19(2.9)$ & $622(95.1)$ & 654 \\
\hline \multicolumn{5}{|l|}{ Oceania } \\
\hline Australia & $2(2.0)$ & $0(0.0)$ & $97(98.0)$ & 99 \\
\hline New Zealand & $0(0.0)$ & $0(0.0)$ & $11(100.0)$ & 11 \\
\hline Region total & $2(1.8)$ & $0(0.0)$ & $108(98.2)$ & 110 \\
\hline Overall totals & $32(1.7)$ & $48(2.5)$ & $1,844(95.8)$ & 1,924 \\
\hline
\end{tabular}


In addition to these 32 consistently resistant accessions (Table 2), $48(2.5 \%)$ others exhibited predominately R to MR reactions. However, this group also exhibited MS to $\mathrm{S}$ reactions within the IT mode across experiments or in individual plants as possible phenotypically mixed accessions (light green and blue highlighted accessions in Supplementary Table S1). Considering the two general groups together, $80(4.2 \%)$ cultivated accessions exhibited exclusively or predominantly $\mathrm{R}$ to $\mathrm{MR}$ reactions across experiments.

Reaction of wild barley accessions. Only 13 (1.4\%) of the 934 wild barley $(H$. vulgare subsp. spontaneum) accessions tested exhibited consistently HR to MR reactions (IT modes ranging from 0 ; to 2) across experiments (Table 4). Similar to cultivated barley, many of the select wild barleys exhibited the full range of $\mathrm{R}$ class ITs from 0; to 2 but some had predominantly IT 0; (WBDC119) (Fig. 1) or predominantly IT 2 (WBDC225) (Table 5). Most of the resistant accessions identified ( 9 of 13) were from the Central Asian countries of Afghanistan (one accession), Kazakhstan (one), Turkmenistan (one), Tajikistan (two), and Uzbekistan (four) (Table 4). Although accessions from the Fertile Crescent comprised more than $85 \%$ of the wild barley germplasm evaluated in this study, only four accessions were found resistant from this region: three from Israel and one from Syria (Table 4).

In addition to the 13 consistently $\mathrm{R}$ wild barley accessions mentioned above (Table 4), 11 (1.2\%) others exhibited predominately $\mathrm{R}$ to MR reactions-but with MS to $\mathrm{S}$ reactions within the IT mode across experiments or in individual plants as possible phenotypically mixed accessions (light green and blue highlighted accessions in Supplementary Table S2). Considering the two general groups together, 24 (2.6\%) wild barley accessions exhibited exclusively or predominantly $\mathrm{R}$ to $\mathrm{MR}$ reactions across experiments.

Reaction of lines with confirmed or putative introgressions from wild Hordeum spp. Of the 55 barley lines with characterized or putative introgressions from various wild Hordeum spp., none was resistant to race TTKSK (Supplementary Table S3). The majority of these lines exhibited ITs of 3- to 3+ but some gave ITs 3-, 2.

Adult plant evaluations in the field. Reaction of susceptible controls and accessions with recognized stem rust resistance genes. The data presented in Table 1 provide a summary of the overall average and range observed for rust severity across experiments, plus the central tendency and variability of IRs for the controls and carriers of known resistance genes. These aggregated data provide an assessment of the consistency of rust reactions across locations and years. The susceptible controls Hiproly and PI 532013 exhibited overall average severities of 23 and 53\%, respectively, in the Kenya nursery and 36 and $71 \%$ in the South Africa nursery. Both of these controls also exhibited predominately S IRs. In contrast, the resistant controls Q21861 and Q/SM20 exhibited much lower overall average severities of 2 and $1 \%$ in the Kenya nursery, respectively, and 4 and $14 \%$ in the South Africa nursery. These two controls also exhibited mostly MR to R IRs.

Chevron (Rpg1), Hietpas-5 (Rpg2), GAW-79 (Rpg3), and Black Hulless (rpgBH) exhibited rust severities intermediate (15 to $22 \%$ ) to those of the resistant and susceptible control groups in Kenya (Table 1). Similar results were found in South Africa, the exceptions being Hietpas-5, which exhibited a lower severity (10\%) than resistant control Q/SM20 (14\%), and Black Hulless (66\%), which exhibited a higher severity than susceptible control Hiproly (36\%). These sources of Rpg1, Rpg2, Rpg3, and $r p h B H$ exhibited mostly MS to S IRs, the exception being Hietpas-5, which had mostly MR IRs in South Africa.

The severity of rust epidemics varied greatly across the different nurseries in Africa. Therefore, the average severity and IRs of susceptible and resistant controls within individual experiments were also presented to provide a proper comparison for the performance of selected cultivated and wild barley accessions.

In the 2014 Kenya nursery infected with races TTKSK and TTKST, disease pressure was moderate because Hiproly and PI 532013 exhibited an average severity of 20 and 53\%, respectively, with IRs of S-MS (Table 3). Disease pressure in the South Africa nurseries infected with race PTKST was low and extremely high in 2012 and 2015, respectively, because Hiproly exhibited an average severity of 5\% (IRs S-MS) and 78\% (IR S), respectively (Table 3). PI 532013 was not included in the 2012 nursery but exhibited an average severity of $100 \%$ (IR S) in the 2015 nursery (Supplementary Fig. S1). Susceptible local wheat controls were heavily infected in all nurseries: Red Bobs exhibited an average severity of $71 \%$ (IR S) in the 2014 Kenya nursery, whereas L37-07 had an average severity of $80 \%$ (IR S) and $95 \%$ (IR S) in the 2012 and 2015 South Africa nurseries, respectively (data not included in tables). The resistant control Q21861 (carrying the rpg4/Rpg5 complex plus $R p g 1$ ) exhibited very low severities and mostly $\mathrm{R}$ IRs (range of $0 \mathrm{R}$ to trace R-MR) in the 2014 Kenya and 2012 South Africa nurseries (Table 3). Under extremely high disease pressure in the 2015 South Africa nursery, Q21861 exhibited a higher average severity of $10 \%$, with IRs of MR to R (Table 3; Supplementary Fig. S1). Q/SM20 (carrying the rpg4/Rpg5 complex only) exhibited slightly higher rust severities than Q21861 in the nurseries where both accessions were included and, in some cases, higher IRs. Chevron (Rpgl only) exhibited very low (2\% severity, with IRs MR-MS), low (14\%, with IRs MS-S), and moderate (36\%, with IRs S-MS) (Table 3; Supplementary Fig. $\mathrm{S} 1)$ rust severities corresponding to the relative disease pressure in the 2012 South Africa, 2014 Kenya, and 2015 South Africa nurseries, respectively.

In the 2014 Kenya and 2012 South Africa nurseries with moderate and low disease pressure, the 32 seedling-resistant selections of cultivated barley ranged in reaction from trace R-MR to $15 \mathrm{~S}-\mathrm{MS}$ and from $0 \% \mathrm{R}$ to $10 \% \mathrm{~S}$, respectively (Table 3 ). Under extreme disease pressure in the 2015 South Africa nursery, nearly all of these 32 selections were overwhelmed, exhibiting severities of 35 to $85 \%$ and IRs of MS to $\mathrm{S}$. The two most resistant accessions identified were BM 9723-53 and Anakin, both exhibiting severities of $15 \%$ with IRs of MR-MS. Other accessions exhibiting lower severities included County (15\%), Paramount (20\%), and BHS 248 (20\%) but they all had MS and S IRs.

Reaction of selected wild barley accessions. Adult plant assessments for many of the selected wild barley accessions could not be obtained in the Kenya nursery because they did not develop to the heading stage. This was likely due to the photoperiod sensitivity of the germplasm growing at an equatorial site. Data were obtained, however, in the South Africa nurseries. In the 2012 South Africa nursery with low disease pressure, the seedling-resistant wild barley selections exhibited reactions ranging from $0 \% \mathrm{R}$ to $20 \% \mathrm{~S}$ (Table 5). As was the case for cultivated barleys, most of the selected wild barley accessions were overwhelmed in the 2015 South Africa nursery, giving reactions ranging from $35 \% \mathrm{~S}$ or MS-S to $60 \% \mathrm{MS}-\mathrm{S}$. The most resistant wild barley accessions identified in this nursery were WBDC 220,224 , and 225, which had lower severities of 20 to $25 \%$ and mostly MR IRs. WBDC 333 exhibited a severity of $25 \%$ but had an S IR.

Molecular assays for Rpg5 and Rpg1 in selected Hordeum accessions with seedling resistance. Molecular assay for Rpg5 to detect a functional rpg4/Rpg5 gene complex. To determine whether any of the selected resistant Hordeum accessions might carry the rpg4/Rpg 5 complex known to be effective against pathotype TTKSK, molecular assays were conducted for a functional Rpg5 gene. In all, 12 of the $32(37.5 \%)$ selected cultivated accessions tested positive for a functional Rpg5 gene (Table 3). Accessions with a functional Rpg5 gene generally had a higher frequency of very low ITs (i.e., the hypersensitive 0 ;) across experiments than those without the gene (Table 3). However, there were exceptions to this trend: Zang Qing 80, possessing a functional Rpg 5 gene, exhibited no 0 ; reactions, and TR 02272 and BM 8923-30, lacking a functional Rpg5 gene, exhibited some 0 ; ITs in two of the three experiments. With respect to adult plant reactions, accessions with a functional Rpg5 gene generally had low rust severities under low (2012 South Africa) and moderate (2014 Kenya) disease pressure; however, other accessions 
lacking the gene also exhibited comparably low rust severities (Table 3).

In total, 11 of the $13(84.6 \%)$ selected wild barley accessions tested positive for a functional Rpg 5 gene (Table 5). No clear trends were observed in the seedling or adult plant reactions between groups of accessions carrying Rpg 5 and those lacking the gene. This comparison was rather limited because the latter group consisted of only two accessions.

The 59 Hordeum accessions (48 cultivated and 11 wild barley) that exhibited predominantly $\mathrm{R}$ to MR reactions or were phenotypically mixed with respect to seedling ITs were also assayed for Rpg5 (light green and blue highlighted accessions in Supplementary Tables S1 and S2). Five cultivated (NB08410, Danuta, BM 9238-15, RD-583, and LAND09-155) and five wild (ICARDA112787, WBDC026, WBDC125, WBDC348, and WBDC349) barley accessions within this group tested positive for the functional gene, indicating the robustness of the seedling evaluations for detecting Rpg5.

Molecular assay to detect a functional Rpg1 gene. The selected cultivated accessions were also assayed for the presence of resistance gene Rpgl to assess whether it might possibly confer residual resistance against a virulent pathotype like TTKSK. Of the 12 accessions carrying a functional Rpg 5 gene, 7 also had a functional Rpgl gene (Table 3). There were no consistent IT trends between accessions carrying both Rpg5 and Rpgl and those carrying only $R p g 5$. Five other accessions were found to carry only Rpg1. Again, no consistent IT trends were observed between accessions carrying only Rpgl and those lacking the two assayed resistance genes. With respect to the adult plant reactions in the field, no strong consistent trends were noted among accessions carrying different combinations of the resistance genes or those lacking the two assayed resistance genes because the range of severities overlapped for the different

TABLE 3. List of cultivated barley accessions exhibiting only resistant (R) to moderately resistant (MR) infection types (IT) to Puccinia graminis f. sp. tritici pathotype TTKSK at the seedling stage, their corresponding adult plant reactions in the field, and results of molecular assays for functional resistance genes

\begin{tabular}{|c|c|c|c|c|c|c|c|c|c|c|c|c|c|c|c|c|}
\hline \multirow[b]{3}{*}{ Accession } & \multirow[b]{3}{*}{ Origin $^{\mathrm{d}}$} & \multirow[b]{3}{*}{ Donor $^{\mathrm{e}}$} & \multicolumn{9}{|c|}{ Seedling reaction to race $\mathrm{TTKSK}^{\mathrm{a}}$} & \multirow{2}{*}{\multicolumn{3}{|c|}{$\frac{\text { Adult plant reaction }^{\mathrm{b}}}{\text { Severity (\%) IR }}$}} & \multirow{2}{*}{\multicolumn{2}{|c|}{ Assay $^{\mathrm{c}}$}} \\
\hline & & & \multicolumn{3}{|c|}{ Experiment 1} & \multicolumn{3}{|c|}{ Experiment 2} & \multicolumn{3}{|c|}{ Experiment 3} & & & & & \\
\hline & & & IT1 & IT2 & GR & IT1 & IT2 & GR & IT1 & IT2 & GR & K 2014 & SA 2012 & SA 2015 & Rpg 5 & Rpgl \\
\hline \multicolumn{17}{|l|}{ Checks } \\
\hline Q21861 & Mexico via Western Australia & $\mathrm{CDC}$ & 0 & 1 & HR-R & 1 & 0 & R-HR & 0 & 1 & HR-R & Tr R-MR & $0 \mathrm{R}$ & $10 \mathrm{MR}-\mathrm{R}$ & + & + \\
\hline Q/SM20 & Saskatoon, SK, Canada & $\mathrm{CDC}$ & 1 & 0 & R-HR & 1 & 0 & R-HR & 1 & 2 & R-MR & 1 MR-MS & $\ldots$ & 14 MR-R & + & - \\
\hline Chevron & Lucerne, Switzerland & USDA & $3-$ & 2 & MS-MR & $3-$ & 2 & MS-MR & 2 & $3-$ & MR-MS & 14 MS-S & 2 MR-MS & 36 S-MS & - & + \\
\hline Hiproly & Ethiopia & USDA & 3 & $3-$ & S-MS & $3-$ & & MS & 3 & & $\mathrm{~S}$ & $20 \mathrm{~S}-\mathrm{MS}$ & 5 S-MS & $78 \mathrm{~S}$ & - & - \\
\hline PI 532013 & Egypt & USDA & 3 & & $\mathrm{~S}$ & 3 & $3+$ & $\mathrm{S}$ & 3 & $3+$ & S & 53 S-MS & $\ldots$ & $100 \mathrm{~S}$ & - & - \\
\hline \multicolumn{17}{|c|}{ Experimental lines } \\
\hline BM 9723-53 & Brandon, Canada & AAFC & 1 & 0 & R-HR & 1 & 0 & R-HR & 0 & 1 & HR-R & $\ldots$ & $\operatorname{Tr}$ MS & 15 MR-MS & + & + \\
\hline SB97197 & Saskatoon, SK, Canada & $\mathrm{CDC}$ & 0 & 1 & HR-R & 2 & 1 & MR-R & 2 & 1 & MR-R & $\ldots$ & $0 \mathrm{R}$ & 45 MS-S & + & + \\
\hline SH98073 & Saskatoon, SK, Canada & $\mathrm{CDC}$ & 0 & 1 & HR-R & 0 & 1 & HR-R & 2 & 1 & MR-R & Tr MR-R & $0 \mathrm{R}$ & $50 \mathrm{~S}-\mathrm{MS}$ & + & + \\
\hline SH98076 & Saskatoon, SK, Canada & $\mathrm{CDC}$ & 0 & $1-$ & HR-R & 0 & 1 & HR-R & 2 & 1 & MR-R & Tr R-MR & $0 \mathrm{R}$ & 45 S-MS & + & + \\
\hline MC0181-11 & Saskatoon, SK, Canada & $\mathrm{CDC}$ & 1 & 2 & R-MR & 1 & 0 & R-HR & 0 & 1 & HR-R & 15 S-MS & $\operatorname{Tr} M R$ & $50 \mathrm{MS}-\mathrm{S}$ & + & + \\
\hline MC0181-31 & Saskatoon, SK, Canada & $\mathrm{CDC}$ & 1 & 0 & R-HR & 2 & 1 & MR-R & 1 & 0 & R-HR & 5 MS-MR & 2 MS-MR & $50 \mathrm{~S}$ & + & + \\
\hline Fusion & Horsens, Denmark & SEJET & 1 & 0 & R-HR & 0 & 1 & HR-R & 0 & 1 & HR-R & 5 MR-R & $0 \mathrm{R}$ & 40 MR-MS & + & $t^{\mathrm{f}}$ \\
\hline Brandham II & Austria & ICARDA & 1 & 0 & R-HR & 1 & 0 & R-HR & 1 & 0 & R-HR & $\ldots$ & $\ldots$ & 35 MR-MS & + & - \\
\hline Anakin & Horsens, Denmark & SEJET & 0 & 1 & HR-R & 0 & 1 & HR-R & 0 & 1 & HR-R & Tr R-MR & $0 \mathrm{R}$ & 15 MR-MS & + & - \\
\hline Otira & Horsens, Denmark & SEJET & 2 & & MR & 1 & 0 & R-HR & 0 & 1 & HR-R & $\ldots$ & $1 \mathrm{~S}$ & 85 S-MS & + & - \\
\hline Zang Qing 148 & Xizang, China & USDA & 1 & 2 & R-MR & 1 & 0 & R-HR & 1 & 2 & R-MR & $\ldots$ & $2 \mathrm{MS}$ & $45 \mathrm{~S}$ & + & - \\
\hline Zang Qing 80 & Xizang, China & USDA & 2 & 1 & MR-R & 1 & 2 & R-MR & 2 & 1 & MR-R & $\ldots$ & 3 S-MS & $70 \mathrm{~S}$ & + & - \\
\hline H94035132 & Lacombe, Canada & FCDC & 2 & 1 & MR-R & 2 & 1 & MR-R & 1 & 2 & R-MR & $\ldots$ & $10 \mathrm{~S}$ & $60 \mathrm{~S}-\mathrm{MS}$ & - & + \\
\hline TR 02272 & Brandon, Canada & AAFC & 0 & 1 & HR-R & 1 & 2 & R-MR & 0 & 1 & HR-R & $\ldots$ & $2 \mathrm{MS}$ & 40 S-MS & - & + \\
\hline 2ND26373 & Fargo, ND & NDSU & 2 & 1 & MR-R & 2 & 1 & MR-R & 1 & 2 & R-MR & $3 \mathrm{MS}$ & $1 \mathrm{~S}$ & $60 \mathrm{~S}-\mathrm{MS}$ & - & + \\
\hline ND23821 & Fargo, ND & NDSU & 2 & & MR & 2 & 1 & MR-R & 2 & 1 & MR-R & $3 \mathrm{MS}$ & $2 \mathrm{MS}$ & 35 MS-S & - & + \\
\hline CLE $202^{\mathrm{h}}$ & Colonia, Uruguay & INIA & 2 & 1 & MR-R & 2 & 1 & MR-R & 2 & 1 & MR-R & $15 \mathrm{MS}-\mathrm{S}$ & $5 \mathrm{~S}$ & $60 \mathrm{~S}-\mathrm{MS}$ & - & + \\
\hline BM 8923-30 & Brandon, Canada & AAFC & 1 & 0 & R-HR & 2 & 1 & MR-R & 0 & 1 & HR-R & 1 MR-MS & $0 \mathrm{R}$ & 35 S-MS & - & - \\
\hline CLE 250 & Colonia, Uruguay & INIA & 2 & 1 & MR-R & 2 & & MR & 1 & 2 & R-MR & $\ldots$ & $2 \mathrm{~S}$ & $50 \mathrm{~S}-\mathrm{MS}$ & - & - \\
\hline Power & Horsens, Denmark & SEJET & 0 & 1 & HR-R & 2 & 1 & MR-R & 2 & 1 & MR-R & Tr MR-MS & $1 \mathrm{MS}$ & 35 S-MS & - & - \\
\hline Magaly & Froissy, France & UNISIGMA & 1 & 2 & R-MR & 2 & 1 & MR-R & 2 & 1 & MR-R & $\ldots$ & $0 \mathrm{R}$ & 30 S-MS & - & - \\
\hline Marigold & Froissy, France & UNISIGMA & 1 & 2 & R-MR & 2 & 1 & MR-R & 2 & 1 & MR-R & $\ldots$ & $2 \mathrm{~S}$ & $50 \mathrm{~S}$ & - & - \\
\hline Onyx & Bergen, Germany & KWS & 1 & 2 & R-MR & 2 & 1 & MR-R & 1 & 2 & R-MR & 3 MR-MS & $\ldots$ & 70 S-MS & - & - \\
\hline BIOS 1 & Russia & Vavilov & 2 & 1 & MR-R & 2 & 1 & MR-R & 1 & 2 & R-MR & $\ldots$ & $1 \mathrm{~S}$ & 45 S-MS & - & - \\
\hline Zadonskij 8 & Russia & Vavilov & 2 & 1 & MR-R & 2 & 1 & MR-R & 1 & 2 & R-MR & $10 \mathrm{MS}$ & $\ldots$ & $50 \mathrm{~S}-\mathrm{MS}$ & - & - \\
\hline County & Cambridge, England & Syngenta & 1 & 2 & R-MR & 2 & 1 & MR-R & 2 & 1 & MR-R & $10 \mathrm{MS}$ & $0 \mathrm{R}$ & 15 S-MS & - & - \\
\hline Macarena & Cambridge, England & LS Plant & 1 & 2 & R-MR & 1 & 0 & R-HR & 2 & 1 & MR-R & 1 MR-MS & $\ldots$ & $35 \mathrm{MS}-\mathrm{S}$ & - & - \\
\hline Paramount & Cambridge, England & LS Plant & 1 & 0 & R-HR & 2 & 1 & MR-R & 1 & 2 & R-MR & $\ldots$ & $\ldots$ & 20 MS-S & - & - \\
\hline BHS 248 & Himachal Pradesh, India & USDA & 2 & 1 & MR-R & 2 & & MR & 2 & 1 & MR-R & $\ldots$ & 2 MS-MR & $20 \mathrm{~S}-\mathrm{MS}$ & - & - \\
\hline Mano & Jiangsu, China & USDA & 2 & & MR & 1 & 2 & R-MR & 1 & 2 & R-MR & Tr R-MR & $3 \mathrm{~S}$ & $75 \mathrm{~S}$ & - & - \\
\hline Cantala & Melbourne, Australia & USDA & 2 & 1 & MR-R & 2 & 1 & MR-R & 2 & 1 & MR-R & Tr R-MR & $\ldots$ & $65 \mathrm{~S}$ & - & - \\
\hline Tallon & Warwick, Australia & USDA & 2 & & MR & 2 & 1 & MR-R & 2 & 1 & MR-R & 5 MS-MR & $1 \mathrm{MS}$ & $50 \mathrm{~S}-\mathrm{MS}$ & - & - \\
\hline
\end{tabular}

a ITs were scored based on the wheat-stem rust system of Stakman et al. (1962), as modified by Miller and Lambert (1955) for barley. IT1 and IT2 represent the most common and the next most common IT observed on accessions within an experiment. Symbols + and - denote more or less sporulation of classically described uredinia, respectively. A general reaction (GR) was assigned for the one or two most common ITs observed, where 0 or 0 ; is highly resistant (HR); 1 is $\mathrm{R} ; 2$ is MR; 3 - is moderately susceptible (MS); and 3, 3+, or 4 is susceptible (S).

b Adult plant reaction was assessed at the mid- to hard-dough stage of development as the percentage of stem and leaf sheath tissue infected by stem rust as estimated using the modified Cobb scale (0 to 100\%) (Peterson et al. 1948) and also as the type of uredinia (i.e., infection response [IR]) observed, where $\mathrm{R}=$ resistant, $\mathrm{MR}=$ moderately resistant, $\mathrm{MS}=$ moderately susceptible, and $\mathrm{S}=$ susceptible (Roelfs et al. 1992). The mean severity is given if more than one replicate was included in the nursery. Trace ( $\mathrm{Tr}$ ) represents a severity of less than $1 \%$. The most common types of uredinia observed on accessions are given in order of their frequency. K 2014 = the 2014 Kenya nursery off season, which had a mixture of pathotypes TTKSK and TTKST, and SA = South Africa nurseries in the years indicated, which were infected with pathotype PTKST; ... indicates data missing or not applicable.

${ }^{c}$ Molecular assays to determine a functional or nonfunctional Rpg5 gene were conducted according to the methods of Arora et al. (2013) and Mamo et al. (2015), and those for Rpgl were done according to Eckstein et al. (2003) as modified by Derevnina et al. (2014). Detailed descriptions of the assays are given in the Materials and Methods section. Symbols: + indicates the presence of the functional gene and - indicates the lack of the functional gene.

${ }^{\mathrm{d}}$ Location of origin for accession.

e Donor institutions: $\mathrm{CDC}=$ Crop Development Centre, USDA = United States Department of Agriculture-Agricultural Research Service National Small Grains Collection, AAFC $=$ Agriculture and Agri-Food Canada, SEJET $=$ SEJET Plant Breeding, ICARDA $=$ International Center for Agricultural Research in the Dry Areas, FCDC $=$ Field Crop Development Centre, NDSU = North Dakota State University, INIA = Instituto Nacional de Investigación Agropecuaria, KWS = KWS LOCHOW GmbH, Vavilov = N. I. Vavilov Institute of Plant Industry, Syngenta $=$ Syngenta Seeds, and LS Plant $=$ LS Plant Breeding Ltd.

${ }^{\mathrm{f}}$ Marker is heterozygous. 
groups (Table 3). BM9723-53 and Anakin were the most resistant accessions identified in the high-disease-pressure nursery in South Africa in 2015. The former carries both Rpg5 and Rpg1 whereas the latter carries only Rpg5. None of the selected wild barley accessions tested positive for a functional Rpgl gene (Table 5).

\section{DISCUSSION}

Pathotypes of $P$. graminis $\mathrm{f}$. sp. tritici in the Ug99 race group represent one of the greatest biotic threats to wheat production in more than 50 years. An extensive international research effort by members of the Borlaug Global Rust Initiative has led to the identification of many new resistance genes effective against these dangerous pathotypes, especially TTKSK (http://www.globalrust. org/). This work has contributed greatly to alleviating the threat posed by these dangerous virulence types to wheat. In contrast, comparatively little research has been advanced on barley even though it is known that pathotype TTKSK also attacks the crop. The present study was undertaken to assess the vulnerability of barley to pathotype TTKSK at the seedling stage and to identify possible sources of resistance. From the evaluation of more than 1,924 cultivated barley accessions to pathotype TTKSK, more than $95 \%$ $(1,844)$ were susceptible (Table 2$)$. Similar results were found in a large panel ( $>3,000$ accessions) of breeding germplasm from the United States (Zhou et al. 2014). Only 32 (1.7\%) cultivated accessions exhibited consistently HR to MR reactions across all experiments (Tables 2 and 3). Evaluation of the wild progenitor (H. vulgare subsp. spontaneum) of cultivated barley revealed a similar high frequency (910 of $934=97.4 \%$ ) of susceptibility to pathotype TTKSK at the seedling stage. Only 13 (1.4\%) wild barley accessions exhibited consistently HR to MR reactions across all experiments (Tables 4 and 5). Finally, 55 barley lines with characterized or putative introgressions from various wild Hordeum spp. were also tested against pathotype TTKSK but none was found to be resistant. Considering all of the Hordeum accessions tested $(2,913)$ in this investigation, over $96 \%(2,809)$ were susceptible as seedlings, indicating the extreme vulnerability of the crop to the African pathotypes of $P$. graminis f. sp. tritici.

The rpg4/Rpg 5 gene complex is the only one described in barley that is highly effective against pathotype TTKSK at the seedling (Steffenson et al. 2009) and adult plant stages. To determine whether any of the resistant Hordeum accessions identified from the seedling phenotyping assays might carry this gene complex, molecular assays were conducted for a functional Rpg 5 gene. In all, 12 of the $32(37.5 \%)$ resistant cultivated accessions and 11 of the 13 (84.6\%) resistant wild barley accessions tested positive for a functional Rpg 5 gene (Tables 3 and 5). This result clearly shows that the overall diversity for resistance in Hordeum is very narrow because more than $51 \%$ of the TTKSK-resistant accessions carry the rpg4/Rpg5 complex. Breeding line Q21861 is the original described source of the rpg4/Rpg 5 gene complex (Brueggeman et al. 2008; Jin et al. 1994; Steffenson et al. 2009). However, subsequent studies have documented the presence of the complex in both Swiss landraces (Mamo et al. 2015; Steffenson et al. 2016) and also the wild progenitor $H$. vulgare subsp. spontaneum (Mamo et al. 2015). Steffenson et al. (2016) found a high frequency (approximately 43\%) of rpg4/Rpg 5 in landraces from the mountainous areas of eastern Switzerland based on a sample of 73 accessions. Although no additional landraces from Switzerland were tested in this study, the rpg4/Rpg5 complex was confirmed in one landrace (Brandham II) from nearby Austria (Table 3). Thus, this area of central Europe (eastern Switzerland and adjacent Austria) is particularly rich with regard to landraces carrying this gene complex. The rpg4/Rpg 5 complex was extremely common in TTKSK-resistant wild barley accessions because more than $84 \%$ were carriers. Accessions with the gene complex were found widely across the $H$. vulgare subsp. spontaneum geographic range from the Fertile Crescent region to Central Asia. However, the highest percentage of resistance, notwithstanding the large differences in sample sizes, was found in accessions from the Central Asian Republics of Tajikistan and Uzbekistan. The relatively common presence of the rpg4/Rpg5 complex in landraces from Switzerland and in wild barley accessions from Central Asia is intriguing. One

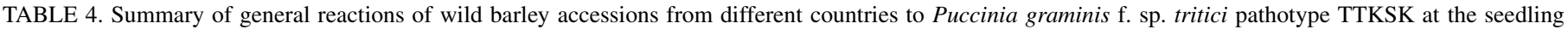
stage

\begin{tabular}{|c|c|c|c|c|}
\hline \multirow[b]{2}{*}{ Country } & \multicolumn{3}{|c|}{ Number $(\%)$ exhibiting reactions ${ }^{\mathrm{a}}$} & \multirow[b]{2}{*}{ Total $^{\mathrm{b}}$} \\
\hline & Only $\mathrm{HR}$ to $\mathrm{MR}$ & $\mathrm{PD} \mathrm{R}$ to $\mathrm{MR}$ or $\mathrm{Seg}$ & Only or PD MS to $\mathrm{S}$ & \\
\hline Afghanistan & $1(9.1)$ & $0(0.0)$ & $10(90.9)$ & 11 \\
\hline Armenia & $0(0.0)$ & $0(0.0)$ & $5(100.0)$ & 5 \\
\hline Azerbaijan & $0(0.0)$ & $0(0.0)$ & $17(100.0)$ & 17 \\
\hline China & $0(0.0)$ & $0(0.0)$ & $8(100.0)$ & 8 \\
\hline Cyprus & $0(0.0)$ & $0(0.0)$ & $3(100.0)$ & 3 \\
\hline Egypt & $0(0.0)$ & $0(0.0)$ & $1(100.0)$ & 1 \\
\hline Iran & $0(0.0)$ & $2(4.8)$ & $40(95.2)$ & 42 \\
\hline Iraq & $0(0.0)$ & $0(0.0)$ & $21(100.0)$ & 21 \\
\hline Israel & $3(0.7)$ & $2(0.4)$ & $444(98.9)$ & 449 \\
\hline Jordan & $0(0.0)$ & $0(0.0)$ & $136(100.0)$ & 136 \\
\hline Kazakhstan & $1(14.3)$ & $0(0.0)$ & $6(85.7)$ & 7 \\
\hline Lebanon & $0(0.0)$ & $0(0.0)$ & $26(100)$ & 26 \\
\hline Libya & $0(0.0)$ & $0(0.0)$ & $11(100.0)$ & 11 \\
\hline Pakistan & $0(0.0)$ & $0(0.0)$ & $2(100.0)$ & 2 \\
\hline Russian Federation & $0(0.0)$ & $0(0.0)$ & $4(100.0)$ & 4 \\
\hline Syria & $1(1.0)$ & $2(2.1)$ & $93(96.9)$ & 96 \\
\hline Tajikistan & $2(25.0)$ & $1(12.5)$ & $5(62.5)$ & 8 \\
\hline Turkey & $0(0.0)$ & $1(2)$ & $38(97.4)$ & 39 \\
\hline Turkmenistan & $1(3.4)$ & $2(6.9)$ & $26(89.7)$ & 29 \\
\hline Uzbekistan & $4(21.1)$ & $1(5.3)$ & $14(73.7)$ & 19 \\
\hline Totals & $13(1.4)$ & $11(1.2)$ & $910(97.4)$ & 934 \\
\hline
\end{tabular}

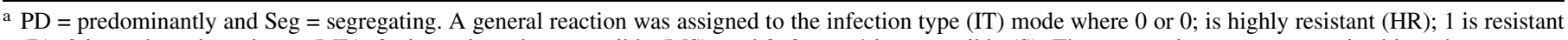
(R); 2 is moderately resistant (MR); 3- is moderately susceptible (MS); and 3, 3+, or 4 is susceptible (S). Then, accessions were categorized into three groups: those exhibiting only $\mathrm{HR}, \mathrm{R}$, or MR reactions across all experiments; those exhibiting predominantly HR, R, or MR reactions within the IT mode across experiments or in individual plants of accessions that were phenotypically mixed due to possible segregation or seed admixtures; and those exhibiting only or predominantly MS to $\mathrm{S}$ reactions within the IT mode across experiments.

b Total number evaluated. 
possible explanation for this is that barberry, the alternate host of $P$. graminis f. sp. tritici, is present and often infected in these regions (Berlin et al. 2014; Steffenson et al. 2016) (M. Rahmatov, personal communication). The persistent presence of the pathogen over a long period of time may have contributed to the evolution of stem rust resistance in these two germplasm pools. With respect to cultivated barley from breeding programs, the rpg4/Rpg 5 complex was found in six lines (SB97197, SH98073, SH98076, MC0181-11, MC0181-31, and BM 9723-53) from two improvement programs in Canada, three cultivars ('Fusion', Anakin, and 'Otira') from one breeding company in Denmark, and two cultivars ('Zang Qing 80' and 'Zang Qing 148') from one institute in China (Table 3). In central and western Canada, stem rust resistance is an important target trait, and use of the rpg4/Rpg5 donor Q28161 was intentional and well-documented (B. Rossnagel and W. Legge, personal communication). In Denmark and China, stem rust is not an important breeding target; thus, the transfer of rpg4/Rpg5 was likely unintentional and the donors unknown. Most of the Canadian breeding lines and all three of the Danish cultivars carrying rpg4/ $R p g 5$ possess good agronomic traits and, therefore, would be useful parents for initiating a program in breeding for resistance to pathotypes of $P$. graminis f. sp. tritici in the $\mathrm{Ug} 99$ race group. All of the Canadian lines with rpg4/Rpg5 also carry Rpgl (Table 3), a gene that has protected barley from significant stem rust losses for more than 70 years in North America (Steffenson 1992). The pyramiding of these genes together in cultivars could provide greater durability for stem rust resistance.

Although the resistance conferred by rpg4/Rpg 5 is quite effective in protecting barley against stem rust, its expression can vary depending on various factors such as genetic background, the presence of other resistance genes, disease pressure, and temperature. Seedling ITs of Hordeum accessions carrying only the
rpg4/Rpg5 complex ranged from predominately 0; (e.g., Anakin and WBDC119) to 2 (e.g., Zang Qing 80 and WBDC225) (Tables 3 and 5). A similar result for rpg4/Rpg 5 carriers was found with respect to adult plant resistance, where rust severities ranged from $15 \%$ (Anakin) to $85 \%$ (Otira) in cultivated barley and from $20 \%$ (WBDC225) to 60\% (WBDC032) in wild barley in the 2015 South Africa nursery where disease pressure was very high (Tables 3 and 5). These data demonstrate a moderate to strong effect of genetic background on the expression of rpg4/Rpg5. Comparison of seedling rust phenotypes between controls Q21861 (rpg4/Rpg5 plus Rpg1) and Q/SM20 (rpg4/Rpg5 only) in this and many other previous experiments revealed that the former consistently exhibits a higher proportion of IT 0; (usually $0 ; 1$ ) than the latter (usually 10;). A similar trend was observed at the adult plant stage in nurseries with heavier rust infection, where Q/SM20 typically exhibits a higher rust severity (Tables 1 and 3). Q/SM20 is a doubled haploid line derived from a cross involving Q21861 (Steffenson et al. 1995). These results suggest a possible epistatic effect of Rpg 1 with $r p g 4 / R p g 5$ in Q21861 or perhaps the influence of other undescribed resistance genes in this line. Other cultivated barley accessions having the same gene combinations (Table 3) as these controls did not exhibit such strong tendencies with respect to either seedling ITs or adult plant rust severity. Previous studies have clearly demonstrated the temperature sensitivity of rpg4/Rpg 5 at the seedling stage: at 18 to $20^{\circ} \mathrm{C}$, the genes confer a high level of resistance (mostly IT 0 ;) to pathotypes such as QCCJB and TTKSK whereas, at temperatures exceeding $27^{\circ} \mathrm{C}$, the genes are rendered completely ineffective (Jin et al. 1994; Sun and Steffenson 1997). In this study, temperature or disease pressure had a marked effect on the level of resistance conferred by rpg4/Rpg 5 at the adult plant stage in South Africa. In 2012, temperatures were near normal during

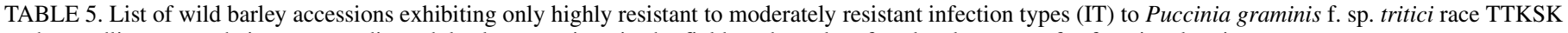
at the seedling stage, their corresponding adult plant reactions in the field, and results of molecular assays for functional resistance genes.

\begin{tabular}{|c|c|c|c|c|c|c|c|c|c|c|c|c|c|c|c|c|c|}
\hline \multirow[b]{3}{*}{ Accession } & \multirow[b]{3}{*}{ Other ${ }^{\mathrm{d}}$} & \multirow[b]{3}{*}{ Location $^{\mathrm{e}}$} & \multirow[b]{3}{*}{ Country ${ }^{\mathrm{f}}$} & \multirow[b]{3}{*}{ Donor ${ }^{\mathrm{g}}$} & \multicolumn{9}{|c|}{ Seedling reaction to race TTKSK $^{\mathrm{a}}$} & \multirow{2}{*}{\multicolumn{2}{|c|}{ Adult plant ${ }^{b}$}} & \multirow{2}{*}{\multicolumn{2}{|c|}{ Assays $^{\mathrm{c}}$}} \\
\hline & & & & & \multicolumn{3}{|c|}{ Experiment 1} & \multicolumn{3}{|c|}{ Experiment 2} & \multicolumn{3}{|c|}{ Experiment 3} & & & & \\
\hline & & & & & IT1 & IT2 & GR & IT1 & IT2 & GR & IT1 & IT2 & GR & 2012 & 2015 & $R p g 5$ & Rpgl \\
\hline \multicolumn{18}{|l|}{ Checks } \\
\hline Q21861 & PI 584766 & Mexico via Western Australia & Mexico & $\mathrm{CDC}$ & 0 & 1 & HR-R & 1 & 0 & R-HR & 0 & 1 & HR-R & $0 \mathrm{R}$ & $10 \mathrm{MR}-\mathrm{R}$ & + & + \\
\hline QSM20 & & Saskatoon & Canada & $\mathrm{CDC}$ & 1 & 0 & R-HR & 1 & 0 & R-HR & 1 & 2 & R-MR & & 14 MR-R & + & - \\
\hline Chevron & PI 38061 & Lucerne & Switzerland & USDA & $3-$ & 2 & MS-MR & $3-$ & 2 & MS-MR & 2 & 3- & MR-MS & 2 MR-MS & $36 \mathrm{~S}-\mathrm{MS}$ & - & + \\
\hline Hiproly & CIho 3947 & - & Ethiopia & USDA & 3 & $3-$ & MS-S & $3-$ & & MS & 3 & & $\mathrm{~S}$ & 5 S-MS & $78 \mathrm{~S}$ & - & - \\
\hline PI 532013 & 2794 & - & Egypt & USDA & 3 & & $\mathrm{~s}$ & 3 & $3+$ & $\mathrm{s}$ & 3 & $3+$ & $\mathrm{s}$ & $\ldots$ & $100 \mathrm{~S}$ & - & - \\
\hline \multicolumn{18}{|c|}{ Experimental lines } \\
\hline ICARDA039 & 38936 & West Bank & Israel & ICARDA & 1 & 0 & R-HR & 2 & 1 & MR-R & 1 & 0 & R-HR & $1 \mathrm{MR}-\mathrm{MS}$ & 35 MS-S & + & - \\
\hline WBDC 014 & 38659 & Baghlan & Afghanistan & ICARDA & 2 & 1 & MR-R & 1 & 2 & R-MR & 1 & 2 & R-MR & $3 \mathrm{MS}$ & $50 \mathrm{MS}-\mathrm{S}$ & + & - \\
\hline WBDC 032 & 38869 & Hazafon & Israel & ICARDA & 1 & 0 & R-HR & 0 & 1 & HR-R & 0 & 1 & HR-R & $2 \mathrm{MR}$ & 60 MS-S & + & - \\
\hline WBDC 119 & 40108 & Dzhizak & Uzbekistan & ICARDA & 0 & 1 & MR-R & 0 & 1 & HR-R & 0 & 1 & HR-R & 7 MS-S & $35 \mathrm{~s}$ & + & - \\
\hline WBDC 209 & 123972 & Dzhizak & Uzbekistan & ICARDA & 1 & 2 & R-MR & 2 & 1 & MR-R & 2 & 1 & MR-R & 5 MS-S & 40 S-MS & + & - \\
\hline WBDC 213 & 124035 & Samarkand & Uzbekistan & ICARDA & 0 & 1 & HR-R & 2 & 1 & MR-R & 2 & & MR & $0 \mathrm{R}$ & $\ldots$ & + & - \\
\hline WBDC 214 & 124046 & Samarkand & Uzbekistan & ICARDA & 2 & 1 & MR-R & 1 & 0 & R-HR & 0 & 1 & HR-R & $2 \mathrm{MR}$ & $35 \mathrm{~S}$ & + & - \\
\hline WBDC 220 & 131642 & Chimkent & Kazakhstan & ICARDA & 1 & 2 & R-MR & 1 & 2 & R-MR & 1 & 2 & R-MR & $20 \mathrm{~S}$ & 25 MR-MS & + & - \\
\hline WBDC 224 & 131790 & Dushanbe & Tajikistan & ICARDA & 2 & 1 & MR-R & 0 & 1 & HR-R & 1 & 0 & R-HR & 2 MS-MR & 25 MR-MS & + & _- \\
\hline WBDC 225 & 131792 & Dushanbe & Tajikistan & ICARDA & 2 & 1 & MR-R & 2 & 1 & MR-R & 2 & 1 & MR-R & 0.5 MR-MS & 20 MR-MS & + & - \\
\hline WBDC 333 & 135478 & Garygalla & Turkmenistan & ICARDA & 2 & 1 & MR-R & 2 & 1 & MR-R & 1 & 2 & R-MR & 2 MR-MS & $25 \mathrm{~S}$ & + & - \\
\hline ICARDA040 & 38947 & Yerushalayim & Israel & ICARDA & 0 & 1 & HR-R & 2 & 1 & MR-R & 1 & 0 & R-HR & $0.5 \mathrm{MR}$ & $50 \mathrm{MR}-\mathrm{MS}$ & - & - \\
\hline WBDC 302 & 38635 & Damascus & Syria & ICARDA & 1 & 2 & MR-R & 0 & 1 & HR-R & 0 & 1 & HR-R & $10 \mathrm{MS}$ & $50 \mathrm{MS}-\mathrm{S}$ & - & - \\
\hline
\end{tabular}

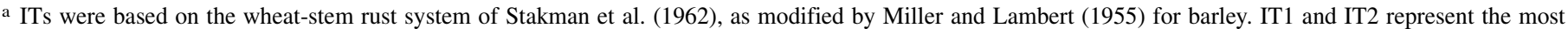
common and the next most common IT observed on accessions within an experiment. Symbols + and - denote more or less sporulation of classically described uredinia, respectively. A general reaction (GR) was assigned for the one or two most common ITs observed, where 0 or 0; is highly resistant (HR); 1 is resistant (R); 2 is moderately resistant (MR); 3- is moderately susceptible (MS); and 3, 3+, or 4 is susceptible (S).

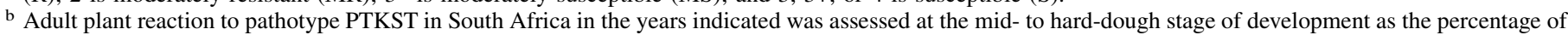
stem and leaf sheath tissue infected by stem rust, estimated using the modified Cobb scale (0 to 100\%) (Peterson et al. 1948) and also as the type of uredinia (i.e., infection response or IR) observed where $\mathrm{R}=$ resistant, $\mathrm{MR}=$ moderately resistant, $\mathrm{MS}=$ moderately susceptible, and $\mathrm{S}=$ susceptible $(\mathrm{Roelfs}$ et al. 1992$)$. The mean severity is given for the controls as more than one replicate was included in the nursery; ... indicates data missing or not applicable.

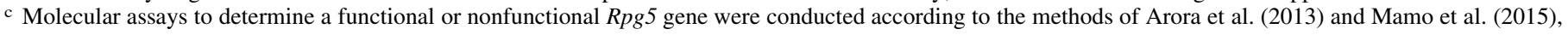
and those for Rpgl were done according to Eckstein et al. (2003), as modified by Derevnina et al. (2014). Detailed descriptions of the assays are given in the Materials and Methods section. Symbols: + indicates the presence of the functional gene and - indicates the lack of the functional gene.

d Other designation.

e Province, region, city, or site.

$\mathrm{f}$ Country of origin.

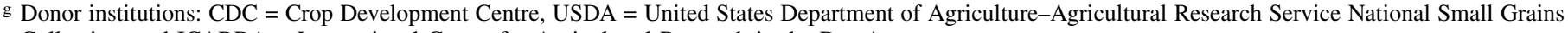
Collection, and ICARDA = International Center for Agricultural Research in the Dry Areas. 
the logarithmic phase of the rust epidemic (October to early November) and inoculum pressure was light. In contrast, temperatures were markedly higher in 2015 during this critical time interval and disease pressure was extraordinarily heavy, due to the late-planted barley crop succumbing to the peak inoculum load coming from adjacent plots of heavily rusted wheat. As a result, severities for cultivated and wild barleys carrying only rpg4/Rpg 5 ranged from just 0 to $3 \%$ and 0 to $7 \%$ in 2012 up to 15 to $85 \%$ and 20 to $60 \%$ in 2015, respectively. Although the rpg $4 /$ Rpg 5 complex generally confers a high level of adult plant resistance in barley based on this and other studies (Zhou et al. 2014), the 2015 South Africa nursery revealed a startling vulnerability: that the resistance genes can be rendered ineffective at elevated temperatures or high inoculum pressure. These factors should be considered when deploying cultivars with the rpg4/Rpg 5 complex.

In addition to accessions with the rpg4/Rpg5 complex, others tested in this study may be useful sources of all-stage or adult plant resistance. With respect to sources of all-stage resistance, there were a number of cultivated and wild barley accessions that exhibited low seedling ITs and rust severities under moderate epidemics and were not carriers of the rpg 4/Rpg 5 complex based on the molecular assay (Tables 3 and 5). Other potentially useful sources of all-stage resistance may be present in the germplasm group, giving predominantly $\mathrm{R}$ to $\mathrm{MR}$ or phenotypically mixed reactions (Supplementary Tables $\mathrm{S} 1$ and $\mathrm{S} 2$ ), but critical adult plant resistance evaluations still need to be done. These potential sources of all-stage resistance are from diverse geographic regions (Tables 2). Adult plant resistance is a particularly important breeding target against stem rust because the disease rarely infects barley until after the heading stage (Zhou et al. 2014). Moreover, this type of resistance may be more durable than all-stage resistance, which is often controlled by one or two genes of major effect (Dyck and Kerber 1985; Ellis et al. 2014). Repeated attempts to obtain robust adult plant resistance data on the entire germplasm panel in both Kenya and South Africa failed several times due to low infection (see below). Therefore, more emphasis was placed on seedling tests because they provide more reliable and consistent stem rust phenotypes than those collected on adult plants in the field and with higher throughput. Although seedling assays may provide useful data on the potential vulnerability of barley to stem rust in the field and also identify accessions with all-stage resistance, they will not reveal accessions carrying only adult plant resistance. It is likely that useful sources of adult plant resistance are present in some of the seedling-susceptible accessions evaluated in this study. This assertion is based on several biparental and genome-wide association mapping studies where quantitative trait loci contributing to low rust severity in adult plants were detected in seedling-susceptible accessions from U.S. breeding programs as well as in carriers of the genes Rpg2 (Hietpas-5) and Rpg3 (GAW 79-3), which are largely ineffective at the seedling stage (Case 2017; Zhou et al. 2014) (unpublished data).

An important factor to consider before using sources of all-stage or adult plant resistance in breeding is whether they will be uniformly effective against all of the widely virulent pathotypes reported in the world. The rpg4/Rpg5 complex is effective against a number of pathotypes in the Ug99 race group at the seedling stage (Case 2017) and to pathotypes TTKSK, TTKST, and PTKST at the adult plant stage under moderate disease pressure. Our current research is focused on screening selected resistant accessions against a suite of diverse pathotypes of $P$. graminis $\mathrm{f}$. sp. tritici and elucidating the genetics of resistance.

The results from this study highlight the potential vulnerability of barley to widely virulent pathotypes like TTKSK. Genetically, barley is more vulnerable to disease outbreaks and other biotic threats than wheat because it is a diploid crop with few wild Hordeum spp. from which to readily transfer new resistance genes (von Bothmer et al. 1995). Bread wheat is an allo-hexaploid species and, therefore, can benefit from the rich diversity of genes in the different genome donors comprising the crop as well as in allied species. It has been genetically enriched through the transfer of many important resistance genes from progenitor and allied species using conventional or specialized cytogenetic techniques (Jiang et al. 1994). Yet, compared with wheat, barley is inherently more resistant to stem rust. This contention is based on the fact that barley frequently exhibits mesothetic reactions, whereby most uredinia are surrounded by chlorosis or necrosis (Sun and Steffenson 2005) and never the fully compatible diamond-shaped uredinia characteristic of IT 4 on wheat (compare PI 532013 and Hiproly versus McNair 701 in Figure 1). Additionally, in rust nurseries where both crops are planted together in the field, barley seldom rusts as heavily as wheat. This inherent or basal resistance may have contributed to the low rust infection observed on barley in most of the African stem rust nurseries where adjacent susceptible wheats exhibited rust severities greatly exceeding $65 \%$. Under commercial production, this basal resistance may protect the barley crop from most epidemics. Still, as clearly demonstrated in this study, many barley accessions, including those carrying the rpg4/Rpg5 complex, can succumb to very high levels of stem rust infection in the field under certain environmental conditions and disease pressure (i.e., South Africa in 2015).

In conclusion, seedling assays revealed the extreme vulnerability of barley to African stem rust pathotypes such as TTKSK. Although most of the resistant Hordeum accessions were found to carry the rpg4/Rpg5 gene complex, other potentially useful sources of resistance were identified in germplasm from diverse regions. Barley possesses a basal level of stem rust resistance in comparison with wheat. Enhancing this basal resistance with rpg4/Rpg5 and other genes in newly discovered resistance sources should provide more durable resistance against the array of different virulence types in the $\mathrm{Ug} 99$ race group.

\section{ACKNOWLEDGMENTS}

This research was funded, in part, by the Lieberman-Okinow Endowment at the University of Minnesota, American Malting Barley Association, USDA-ARS Cooperative Agreement 58-5062-5-012 (Understanding Stem Rust Resistance in Barley and Germplasm), the Bill \& Melinda Gates Foundation, and the UK Department for International Development to Cornell University for the Borlaug Global Rust Initiative Durable Rust Resistance in Wheat Project. We thank S. Dahl, T. Szinyei, M. Martin, and P. Olivera for excellent technical assistance; and D. Singh for assistance in establishing the early rust screening nurseries in Kenya. We thank all of the cooperators who kindly donated seed for this investigation.

\section{LITERATURE CITED}

Ames, N., Dreiseitl, A., Steffenson, B. J., and Muehlbauer, G. J. 2015. Mining wild barley for powdery mildew resistance. Plant Pathol. 64:1396-1406.

Arora, D., Gross, T., and Brueggeman, R. 2013. Allele characterization of genes required for $r p g 4$-mediated wheat stem rust resistance identifies Rpg5 as the $R$ gene. Phytopathology 103:1153-1161.

Bariana, H. S., Brown, G. N., Bansal, U. K., Miah, H., Standen, G. E., and Lu, M. 2007. Breeding triple rust resistant wheat cultivars for Australia using conventional and marker-assisted selection technologies. Aust. J. Agric. Res. 58:576-587.

Berlin, A., Rahmatov, M., Muminjanov, H., and Yuen, J. 2014. Sexual reproduction contributes to genotypic variation in the population of Puccinia graminis in Tajikistan. Eur. J. Plant Pathol. 141:159-168.

Browder, L. 1971. Pathogenic specialization in cereal rust fungi, especially Puccinia recondita $\mathrm{f}$. sp. tritici: Concepts, methods of study, and application. U. S. Dep. Agric. Agric. Res. Serv. Tech. Bull. 1432.

Brueggeman, R., Druka, A., Nirmala, J., Cavileer, T., Drader, T., Rostoks, N., Mirlohi, A., Bennypaul, H., Gill, U., Kidma, D., Whitelaw, C., Kilian, A., Han, F., Sun, Y., Gill, K., Steffenson, B., and Kleinhofs, A. 2008. The stem rust resistance gene Rpg5 encodes a protein with nucleotide-binding-site, leucine-rich, and protein kinase domains. Proc. Natl. Acad. Sci. USA 105: $14970-14975$.

Case, A. J. 2017. Genetics, sources, and mapping of stem rust resistance in barley. Ph.D. Dissertation, University of Minnesota, St. Paul.

Cereal Rust Bulletin. Online publication. https://www.ars.usda.gov/midwestarea/st-paul-mn/cereal-disease-lab/docs/cereal-rust-bulletins/cereal-rustbulletins/ 
Cereal Rust Bulletin. 2012. Online publication by the USDA-ARS Cereal Disease Laboratory. https://www.ars.usda.gov/ARSUserFiles/50620500/ Cerealrustbulletins/12CRB9\%20fin.pdf

Derevnina, L., Fetch, T., Singh, D., Brueggeman, R. S., Dong, C., and Park, R. 2014. Analysis of stem rust resistance in Australian barley cultivars. Plant Dis. 98:1485-1493.

Dill-Macky, R., Rees, R. G., and Platz, G. J. 1991. Inoculum pressure and the development of stem rust epidemics in barley. Aust. J. Agric. Res. 42: 769-777.

Duplessis, S., Cuomo, C. A., Lin, Y.-C., Aerts, A., Tisserant, E., Veneault-Fourrey, C., Joly, D. L., Hacquard, S., Amselem, J., Cantarel, B. L., Chiu, R., Coutinho, P. M., Feau, N., Field, M., Frey, P., Gelhaye, E., Goldberg, J., Grabherr, M. G., Kodira, C. D., Kohler, A., Kües, U., Lindquist, E. A., Lucas, S. M., Mago, R., Mauceli, E., Morin, E., Murat, C., Pangilinan, J. L., Park, R., Pearson, M., Quesneville, H., Rouhier, N., Sakthikumar, S., Salamov, A. A., Schmutz. J., Selles, B., Shapiro, H., Tanguay, P., Tuskan, G. A., Henrissat, B., Van de Peer, Y., Rouzé, P., Ellis, J. G., Dodds, P. N., Schein, J. E., Zhong, S., Hamelin, R. C., Grigoriev, I. V., Szabo, L. J., and Martin, F. 2011. Obligate biotrophy features unraveled by the genomic analysis of rust fungi. Proc. Natl. Acad. Sci. USA 108: 9166-9171.

Dyck, P. L., and Kerber, E. R. 1985. Resistance of the race-specific type. Pages 469-500 in: The Cereal Rusts, Volume II: Diseases, Distribution, Epidemiology, and Control. A. P. Roelfs and W. R. Bushnell, eds. Academic Press, Orlando, FL.

Eckstein, P., Rossnagel, B., and Scoles, G. 2003. Allele-specific markers within the barley stem rust resistance gene (Rpg1). Barley Genet. Newsl. 33:7-11.

Ellis, J. E., Lagudah, E. S., Spielmeyer, W., and Dodds, P. N. 2014. The past, present and future of breeding rust resistant wheat. Front. Plant Sci. 5:641.

Fetch, T., Johnston, P. A., and Pickering, R. 2009. Chromosomal location and inheritance of stem rust resistance transferred from Hordeum bulbosum into cultivated barley (H. vulgare). Phytopathology 99:339-343.

Gorbunova, Y. V. 1979. Breeding barley for resistance to stem rust. Sel. Semenovod. 4:15.

Grando, S., and Gomez Macpherson, H. 2005. Food Barley: Importance, Uses and Local Knowledge. International Center for Agricultural Research in the Dry Areas (ICARDA), Aleppo, Syria.

Harder, D. E., and Dunsmore, K. M. 1991. Incidence and virulence of Puccinia graminis f. sp. tritici on wheat and barley in Canada in 1990. Can. J. Plant Pathol. 13:361-364.

Jedel, P. 1990. A gene for resistance to Puccinia graminis f. sp. tritici in PI 382313. Barley Genet. Newsl. 20:43-44.

Jedel, P. E., Metcalfe, D. R., and Martens, J. W. 1989. Assessment of barley accessions PI 382313, PI 382474, PI 382915, and PI 382976 for stem rust resistance. Crop Sci. 29:1473-1477.

Jiang, J., Friebe, B., and Gill, B. S. 1994. Recent advances in alien gene transfer in wheat. Euphytica 73:199-212.

Jin, Y., and Singh, R. P. 2006. Resistance in U.S. wheat to recent Eastern African isolates of Puccinia graminis f. sp. tritici with virulence to resistance gene Sr31. Plant Dis. 90:476-480.

Jin, Y., Steffenson, B. J., and Miller, J. D. 1994. Inheritance of resistance to pathotypes QCC and MCC of Puccinia graminis f. sp. tritici in barley line Q21861 and temperature effects on the expression of resistance. Phytopathology 84:452-455.

Jin, Y., Szabo, L. J., Pretorius, Z. A., Singh, R. P., Ward, R., and Fetch, T. 2008. Detection of virulence to resistance gene $\operatorname{Sr} 24$ within race TTKS of Puccinia graminis f. sp. tritici. Plant Dis. 92:923-926.

Leonard, K., and Szabo, L. 2005. Pathogen profile: Stem rust of small grains and grasses caused by Puccinia graminis. Mol. Plant Pathol. 6:99-111.

Mamo, B. E., Brueggeman, R. S., Smith, K. P., and Steffenson, B. J. 2015. Genetic characterization of resistance to wheat stem rust race TTKSK in landrace and wild barley accessions identifies the rpg4/Rpg5 locus. Phytopathology 105:99-109.

Martens, J. W., Dunsmore, K. M., and Harder, D. E. 1989. Incidence and virulence of Puccinia graminis in Canada on wheat and barley in 1988. Can. J. Plant Pathol. 11:424-430.

McVey, D. V., Long, D. L., and Roberts, J. J. 2002. Races of Puccinia graminis in the United States during 1997 and 1998. Plant Dis. 86:568-572.

Miller, J. D., and Lambert, J. W. 1955. Variability and inheritance of reaction of barley to race 15B of stem rust. Agron. J. 47:373-377.

Murray, M., and Thompson, W. 1980. Rapid isolation of high molecular weight plant DNA. Nucleic Acids Res. 8:4321-4326.

Mwando, K. E., Tabu, I. M., Otaye, O. D., and Njau, P. N. 2012. Effect of stem rust on the quality of selected barley genotypes. ISRN Agron. 2012:1-8.

Nazari, K., Mafi, M., Yahyaoui, A., Singh, R., and Park, R. 2009. Detection of wheat stem rust (Puccinia graminis f. sp. tritici) race TTKSK (Ug99) in Iran. Plant Dis. 93:317.
Njau, P. N., Bhavani, S., Huerta-Espino, J., Keller, B., and Singh, R. P. 2013. Identification of QTL associated with durable adult plant resistance to stem rust race Ug99 in wheat cultivar "Pavon 76.". Euphytica 190:33-44.

Park, R. F. 2007. Stem rust of wheat in Australia. Aust. J. Agric. Res. 58: 558-566.

Patpour, M., Hovmøller, M., Justesen, A., Newcomb, M., Olivera, P., Jin, Y., Szabo, L. J., Shahin, A. A., Wanyera, R., Habarurema, I., and Wobibi, S. 2016. Emergence of virulence to SrTmp in the Ug99 race group of wheat stem rust, Puccinia graminis f. sp. tritici, in Africa. Plant Dis. 100: 522.

Patterson, F., Shands, R., and Dickson, J. 1957. Temperature and seasonal effects on seedling reactions of barley varieties to three races of Puccinia graminis f. sp. tritici. Phytopathology 47:395-402.

Peterson, R., Campbell, A., and Hannah, A. 1948. A diagrammatic scale for estimating rust intensity on leaves and stems of cereals. Can. J. Res. 26c: 496-500.

Powers, L., and Hines, L. 1933. Inheritance of reaction to stem rust and barbing of awns in barley crosses. J. Agric. Res. 46:1121-1129.

Pretorius, Z. A., Singh, R. P., Wagoire, W. W., and Payne, T. S. 2000. Detection of virulence to wheat stem rust resistance gene Sr31 in Puccinia graminis f. sp. tritici in Uganda. Plant Dis. 84:203.

Pretorius, Z. A., Szabo, L. J., Boshoff, W. H. P., Herselman, L., and Visser, B. 2012. First report of a new TTKSF race of wheat stem rust (Puccinia graminis f. sp. tritici) in South Africa and Zimbabwe. Plant Dis. 96:590.

Roelfs, A. P. 1978. Estimated losses caused by rust in small grain cereals in the United States 1918-76. U. S. Dep. Agric. Agric. Res. Serv. Misc. Publ. No. 1363.

Roelfs, A. P. 1982. Effects of barberry eradication on stem rust in the United States. Plant Dis. 66:177-181.

Roelfs, A. P., Long, D. L., and Roberts, J. J. 1993a. Races of Puccinia graminis in the United States during 1990. Plant Dis. 77:125-128.

Roelfs, A. P., Long, D. L., and Roberts, J. J. 1993b. Races of Puccinia graminis in the United States during 1991. Plant Dis. 77:129-132.

Roelfs, A. P., and Martens, J. W. 1988. An international system of nomenclature for Puccinia graminis f. sp. tritici. Phytopathology 78:526-533.

Roelfs, A. P., Singh, R. P., and Saari, E. E. 1992. Rust Diseases of Wheat: Concepts and Methods of Disease Management. Centro Internacional de Mejoramiento de Maíz y Trigo (CIMMYT), D.F., Mexico.

Rowell, J. B. 1985. Controlled infection by Puccinia graminis f. sp. tritici under artificial conditions. Pages 291-332 in: The Cereal Rusts Volume I. Origins, Specificity, Structure, and Physiology. W. R. Bushnell and A. P. Roelfs, eds. Academic Press, Orlando, FL.

Roy, J. K., Smith, K. P., Muehlbauer, G. J., Chao, S., Close, T. J., and Steffenson, B. J. 2010. Association mapping of spot blotch resistance in wild barley. Mol. Breed. 26:243-256.

RustTracker.org. 2016. A Global Wheat Rust Monitoring System. Status Summary: Ug99 Lineage-February 2016. Published Online. http://rusttracker. cimmyt.org/

Schooler, A. 1974. Registration of North Dakota 1381 and 2749 barley germplasm. Crop Sci. 14:609-610.

Schooler, A., and Franckowiak, J. D. 1981. Registration of North Dakota 497 and 586 barley germplasm. Crop Sci. 21:352.

Shands, R. 1939. Chevron, a barley variety resistant to stem rust and other diseases. Phytopathology 29:209-211.

Singh, R. P., Hodson, D. P., Huerta-Espino, J., Jin, Y., Bhavani, S., Njau, P. 2011. The emergence of Ug99 races of the stem rust fungus is a threat to world wheat production. Annu. Rev. Phytopathol. 49:465-481.

Singh, R. P., Hodson, D. P., Huerta-Espino, J., Jin, Y., Njau, P., Wanyera, R., Herrera-Foessel, S. A., and Ward, R. W. 2008. Will stem rust destroy the world's wheat crop? Pages 271-309 in: Advances in Agronomy, Vol. 98. D. L. Sparks, ed. Elsevier Inc., San Diego, CA.

Singh, R. P., Hodson, D. P., Jin, Y., Huerta-Espino, J., Kinyua, M. G., Wanyera, R., Njau, P., and Ward, R. W. 2006. Current status, likely migration and strategies to mitigate the threat to wheat production from race Ug99 (TTKS) of stem rust pathogen. CAB Rev. Perspect. Agric. Vet. Sci. Nutr. Nat. Resour. 1:054

Singh, R. P., Hodson, D. P., Jin, Y., Lagudah, E. S., Ayliffe, M. A., Bhavani, S., Rouse, M. N., Pretorius, Z. A., Szabo, L. J., Huerta-Espino, J., Basnet, B. R., Lan, C., and Hovmøller, M. S. 2015. Emergence and spread of new races of wheat stem rust fungus: Continued threat to food security and prospects of genetic control. Phytopathology 105:872-884.

Singh, R. P., William, H. M., Huerta-Espino, J., and Rosewarne, G. 2004. Wheat rust in Asia: Meeting the challenges with old and new technologies. Pages 1-13: In Proc. 4th Int. Crop Sci. Congr. Brisbane, Australia.

Stakman, E. C., Stewart, D. M., and Loegering, W. Q. 1962. Identification of physiologic races of Puccinia graminis var. tritici. U. S. Dep. Agric. Agric. Res. Serv. Bull. E617.

Steffenson, B., Zhou, H., Chai, Y., and Grando, S. 2012. Vulnerability of cultivated and wild barley to African stem rust race TTKSK. Pages 
243-255: In Proc. 11th Int. Barley Genet. Symp. G. Zhang, C. Li, and X. Liu, eds. Hangzhou, China.

Steffenson, B. J. 1992. Analysis of durable resistance to stem rust in barley. Euphytica 63:153-167.

Steffenson, B. J., Jin, Y., Brueggeman, R. S., Kleinhofs, A., and Sun, Y. 2009. Resistance to stem rust race TTKSK maps to the rpg4/Rpg5 complex of chromosome 5H of barley. Phytopathology 99:1135-1141.

Steffenson, B. J., Jin, Y., Rossnagel, B. G., Rasmussen, J. B., and Kao, K. 1995. Genetics of multiple disease resistance in a doubled-haploid population of barley. Plant Breed. 114:50-54.

Steffenson, B. J., Olivera, P., Roy, J. K., Jin, Y., Smith, K. P., and Muehlbauer, G. J. 2007. A walk on the wild side: Mining wild wheat and barley collections for rust resistance genes. Aust. J. Agric. Res. 58:532-544.

Steffenson, B. J., Solanki, S., and Brueggeman, R. S. 2016. Landraces from mountainous regions of Switzerland are sources of important genes for stem rust resistance in barley. Alp. Bot. 126:23-33.

Steffenson, B. J., Wilcoxson, R. D., and Roelfs, A. P. 1984. Inheritance of resistance to Puccinia graminis f. sp. secalis in barley. Plant Dis. 68:762-763.

Sun, Y., and Steffenson, B. J. 1997. Effect of incubation time and temperature on the phenotypic expression of rpg4 to Puccinia graminis f. sp. tritici in barley. Can. J. Plant Pathol. 19:25-29.

Sun, Y., and Steffenson, B. J. 2005. Reaction of barley seedlings with different stem rust resistance genes to Puccinia graminis f. sp. tritici and Puccinia graminis f. sp. secalis. Can. J. Plant Pathol. 27:80-89.
Sun, Y., Steffenson, B. J., and Jin, Y. 1996. Genetics of resistance to Puccinia graminis f. sp. secalis in barley line Q21861. Phytopathology 86: 1299-1302.

Ullrich, S. E. 2011. Barley: Production, Improvement, and Uses. WileyBlackwell, Ames, IA.

USDA-ARS. 2016. Cereal Disease Laboratory, Small Grain Losses Due to Rust. Online publication. https://www.ars.usda.gov/midwest-area/st-paul-mn/ cereal-disease-lab/docs/small-grain-losses-due-to-rust/small-grain-lossesdue-to-rust/.

von Bothmer, R., Jacobson, N., Baden, C., Jorgensen, R., and Laursen Linde, I. 1995. An Ecogeographical Study of the Genus Hordeum, 2nd ed. International Plant Genetics Resources Institute, Rome.

Wanyera, R., Kinyua, M. G., Jin, Y., and Singh, R. P. 2006. The spread of stem rust caused by Puccinia graminis f. sp. tritici, with virulence on $\mathrm{Sr} 31$ in wheat in Eastern Africa. Plant Dis. 90:113.

Wendler, N., Mascher, M., Himmelbach, A., Johnston, P., Pickering, R., and Stein, N. 2015. Bulbosum to go: A toolbox to utilize Hordeum vulgarel bulbosum introgressions for breeding and beyond. Mol. Plant 8: 1507-1519.

Zadoks, J. C., Chang, T. T., and Konzak, C. F. 1974. A decimal code for the growth stages of cereals. Weed Res. 14:415-421.

Zhou, H., Steffenson, B. J., Muehlbauer, G., Wanyera, R., Njau, P., and Ndeda, S. 2014. Association mapping of stem rust race TTKSK resistance in US barley breeding germplasm. Theor. Appl. Genet. 127:1293-304. 